\title{
The Development and Application of a Scuffing Test Based on Contra- rotation
}

\author{
Bo Peng ${ }^{1} \cdot$ Hugh Spikes ${ }^{1} \cdot$ Amir Kadiric $^{1}$ (D)
}

Received: 13 November 2018 / Accepted: 11 February 2019 / Published online: 25 February 2019

(c) The Author(s) 2019

\begin{abstract}
Scuffing is a surface failure mode that occurs in sliding-rolling contacts subjected to high loads and high sliding speeds, such as those in gears and cam-followers. Owing to its sudden onset, rapid progression and dependence on both fluid and boundary lubricant films, scuffing is difficult to study in a repeatable manner. This paper describes further development of a recently proposed scuffing test method based on contra-rotation, its extension to higher loads using a new experimental set-up and its application to study the onset of scuffing with a selection of model and fully-formulated oils. The method employs two surfaces moving in opposite directions under rolling-sliding conditions, with a fixed load and step-wise increasing sliding speed. By decoupling the entrainment and sliding speeds, the method allows the effects of lubricant formulation on scuffing performance to be isolated from the influence of viscosity. The approach achieves high sliding speeds in parallel with low entrainment speeds, while minimising the undesirable effects of surface wear and frictional heating. The proposed test is relatively fast and economical, with total test time of about $30 \mathrm{~min}$ including specimen cleaning and set-up. Results show that the newly implemented modifications have improved the repeatability of the test method, so that the number of repeat tests required for reliable oil ranking results is minimal. Tests with model and fully-formulated oils show that the onset of scuffing is characterised by a sharp and unrecoverable increase in friction and accompanied by the destruction of any boundary films. All tests show that the relationship load $\times$ speed $^{n}=$ constant holds at scuffing, with the exact value of the exponent $n$ being dependent on the oil formulation. Additivised oils were shown to have enhanced scuffing resistance, which arises from their ability to postpone the uncontrollable rise in friction to higher sliding speeds. Finally, the critical maximum contact temperature scuffing criterion was shown to predict the onset of scuffing in our tests better than the frictional power intensity criterion.
\end{abstract}

Keywords Scuffing $\cdot$ Scoring $\cdot$ Smearing $\cdot$ Scuffing test $\cdot$ Gear

\section{Introduction}

Scuffing is defined as "gross damage characterised by the formation of local welds between sliding surfaces" [1]. The damaged surfaces exhibit a torn, dragged appearance, and some transfer of material between the surfaces is usually present. Scuffing generally occurs in sliding-rolling contacts that operate under relatively high sliding speeds. It is therefore one of the major failure modes in gears and sliding cam-follower contacts, but can also occur in rolling bearings where it is commonly termed "smearing". The first reports

Amir Kadiric

a.kadiric@imperial.ac.uk

1 Tribology Group, Imperial College London, SW7 2AZ London, UK of scuffing in practical applications date back to 1920s, when automotive hypoid gears, which experience relatively high slide-roll ratios (SRRs), were observed to suffer this type of damage [2]. Scuffing is a catastrophic type of failure as it starts suddenly and progresses very quickly due to a strong thermal feedback mechanism. This is in contrast to many other tribological failure modes of relevance to gears and bearings such as rolling contact fatigue and mild wear, which are cumulative and hence the damage progression is slower and final failure can often be predicted. This sudden onset and fast progression means that scuffing is quite challenging to study experimentally since it is difficult to ensure reasonable repeatability of test results-there is no cumulative averaging. This in turn means that the precise mechanisms leading to scuffing are relatively poorly understood and that there are no universally accepted scuffing criteria. 
In order for scuffing to occur, adhesive forces between the contacting surfaces need to be high, which generally implies that all protective lubricant films must have collapsed, i.e. all three of the hydrodynamic fluid film, any micro-elastohydrodynamic (EHL) film present in asperity micro-contacts and any boundary films formed through interaction of lubricant additives with rubbing surfaces must be destroyed prior to the onset of scuffing [3-5]. Scuffing damage progresses very quickly owing to a strong thermal feedback mechanism: any onset of scuffing on a local level is followed by a rapid increase in contact friction, which leads to increased surface temperatures and therefore a further collapse of lubricant films and consequently more scuffing damage. Given this general mechanism, random variations in surface roughness or local friction can trigger a sudden and unexpected onset of scuffing, and in practice, it is not unusual to observe two seemingly identical machines have very different scuffing performance. Some practical examples of scuffing include those in gears, large slow rotating bearings, where the rolling elements undergo significant slowdown in the unloaded zone and so experience high sliding speeds at the re-entry to the loaded zone [6], for example in wind turbine gearbox bearings [7], piston ring liner contacts in combustion engines [8] and cam-followers. If left unchecked, scuffing can lead to the affected components losing their surface integrity and functionality, resulting in a shutdown of the affected system with associated downtime costs.

The ongoing trend for reduction in lubricating oil viscosities in the search of improving efficiency of mechanical systems, changes in additive package chemistries and increasing power densities of machines, all contribute to an increasing risk of scuffing damage, which makes this work timely. One example of a modern application where oil scuffing resistance is increasingly important is the geared turbo-fan engine where the aviation turbine lubricant formulations are now expected to provide protection not just to the engine parts, but also to the gearbox itself, where the increased sliding and relatively low specific film thicknesses can present different and competing requirements.

Given its practical significance, several authors have studied the mechanisms of scuffing and used these to help devise predictive criteria for the onset of scuffing. The earliest and by-far the most widely applied scuffing criteria is due to Blok [9] who proposed that, for a given lubricant-material combination, scuffing will occur when the contact maximum instantaneous temperature reaches some critical value. Following the subsequent realisation of the importance of EHL films in lubricated contact performance, Dyson and colleagues $[10,11]$ proposed that scuffing occurs due to EHL film collapse caused by an increase in contact inlet temperature. This is in contrast to Blok's in-contact temperature due to frictional heating within the sliding contact. More recent scuffing models include ones based on asperity plastic deformation [12], the collapse of EHL film due to debris accumulation in the inlet [13], surface chemical film desorption [14] and adiabatic shear instability [15-17]. Dyson [18], Ludema [19] and more recently, Bowman and Stachowiak [20] provide comprehensive overviews of proposed scuffing mechanisms.

Given the sensitivity of scuffing onset to small variations in local contact conditions and rapid progression, it is perhaps not surprising that there appears to be no single criteria that is universally applicable to all lubricants and contact conditions. One of the key issues lies in the fact that, depending on the specific conditions imposed, different test methods may be evaluating different things in terms of scuffing resistance for the same lubricant-material combination. Since all protective lubricant films must break down for scuffing to occur, a given test may be evaluating either the strength of the boundary film, the strength of the EHL film or some complex combination of the two. The problem is succinctly described by Ingram et al. [4] using the scuffing transition diagrams of De Gee et al. [5]. It means that tests are generally unable to distinguish between the scuffing resistance provided by the fluid film, which is heavily dependent on lubricant's viscosity, and that provided by the boundary film, which is determined by the lubricant's additive package. Since the onset of scuffing normally requires a considerable sliding speed, there is always a significant EHL film present just prior to scuffing, so that the lubricant viscosity will have a major effect on the lubricant test ranking regardless of the effectiveness of its additive package on scuffing resistance.

Additional problems arise in scuffing tests where pure sliding is employed, such as the four-ball [21] or the Timken [22] tests, where one of the bodies is stationary and the load is increased in steps until scuffing occurs. Here, the surface of the stationary component can suffer considerable wear as the test progresses, so that the contact pressure for a given load in the later stages of the test is reduced from that which would be expected for an unworn component. In extreme cases, this may lead to a lubricant with poor wear prevention exhibiting enhanced scuffing resistance. The step-wise increase in load also means that new, fresh regions of the rubbing surfaces with no boundary layer protection are brought into contact at the start of every load step. This produces a characteristic spike in friction as the load is increased and may itself promote the onset of scuffing. Gear scuffing tests such as the back-to-back gear tests, Ryder [23], IAE [24] and FZG [25], employ sliding-rolling conditions so the wear volume is distributed over a large surface area and little reduction of pressure occurs during a test. Practical problems with these tests include the fact that at the speeds and loads needed to achieve scuffing, the frictional heat input is considerable, which leads to unpredictable increases in tooth bulk temperature and hence poorly 
defined scuffing conditions. Also the maximum achievable load and sliding speed are limited by gear design, so that it may not be possible to achieve scuffing at all with some modern high performance gear oils.

To address some of the above issues, in 2015 Ingram et al. [4] devised a new scuffing test in which the two contacting surfaces move in opposite directions. Use of such contrarotation means that the sliding speed can be increased in stages while keeping the entrainment speed at a low and constant value. Additionally, because both surfaces move with respect to the contact the wear is distributed around the wear tracks, avoiding significant reductions of contact pressure due to wear.

Ingram et al.'s method represents an important advance in producing a controlled-condition scuffing test that can be used to explore scuffing mechanisms. However, the authors identified two potential problems: (i) the variability in the obtained results was rather high and (ii) there was uncertainty in the applicability of standard EHD theories to film thickness predictions in contra-rotating contacts under zero or very low entrainment speeds due to a potential formation of a central dimple [26-28].

The aims of the present work were therefore to develop Ingram et al.'s contra-rotation method further into a useful scuffing test and, in particular, to address the following;

- To improve the repeatability of the method by introducing modifications to the test procedure and by investigating whether the 'dimple' effect is present under the range of conditions employed.

- To use a recently developed high load mini-tractionmachine (MTM) to explore the onset of scuffing over a wider speed and contact pressure range.

- Having demonstrated the reliability of the improved method, to use it to study the onset of scuffing with a selection of lubricating oils, including base stocks and fully-formulated industrial and aviation turbine oils.

- To assess the ability of the existing scuffing criteria to predict the onset of scuffing in the present tests.

\section{Development of the Test Methodology}

Conventional test methods used in scuffing research employ either a pure sliding (e.g. block on ring, four-ball) or sliding-rolling contact (e.g. back-to-back gear set-ups) with step-wise increase in load until scuffing occurs. There are four main limitations of this approach.

i. Firstly, tests applying pure sliding motion result in significant cumulative wear of the stationary surfaces. This leads to a drop in contact pressure at a given test load as the test progresses. It also creates addi- tional problems when using oils containing anti-wear additives, since by reducing wear these may result in higher contact pressures at a given load stage. This means that the intrinsic scuffing propensity of different oils cannot be ranked reliably.

ii. Secondly, the conventional increasing-load test sequence used in pure sliding tests exposes fresh surface at the edge of the previous contact area at the beginning of each load step. This raises the possibility of direct contact between unprotected asperities, which in turn increases the risk of scuffing onset.

iii. A third problem that occurs in both pure sliding and rolling-sliding tests is that the high sliding speed necessary to promote scuffing is accompanied by high entrainment speed. With smooth surfaces this will initially result in a separating EHL film. A scuffing test thus involves successive breakdown of both an EHL and a boundary film, so that lubricants with high viscosities that form thick EHL films will tend to appear more effective at preventing scuffing than low viscosity ones.

iv. A fourth, very significant problem in both pure sliding and sliding-rolling tests is that the high sliding speed necessary to promote scuffing results in a large rate of heat generation and this can produce a considerable rise in temperature of the test specimens during a test. Consequently, an EHL film will become thinner as the bulk temperature of the rubbing specimens increases during a test, so the contact conditions at scuffing are very poorly defined.

These issues make it difficult to study the inherent scuffing resistance of different oil types or to isolate the influence of a single contact condition of interest, such as is needed to provide better insight into the mechanisms of scuffing.

In 1946 Blok [29] used a counter-rotation motion in a two disc machine to study scuffing. The basic counter-rotation method is illustrated in Fig. 1. This approach eliminates the first and third problems identified above: by using a rolling-sliding set-up the problem of excessive wear depth is eliminated, while the counter rotation makes it possible to decouple sliding and entrainment speeds. Blok himself employed pure contra-rotation with identical but opposite surface speeds and hence theoretically zero entrainment speed. More recently, Ingram et al. [4] used this counterrotation approach in a ball-on-disc set-up (PCS Instruments MTM rig). They made no attempt to operate in pure contrarotation, which they realised was practicably unattainable, but instead employed low but controllable, entrainment speeds while varying sliding speed. They also implemented important modifications to address the second and fourth problem identified above. They introduced a 'rest stage', consisting of pure rolling motion, in between each testing 


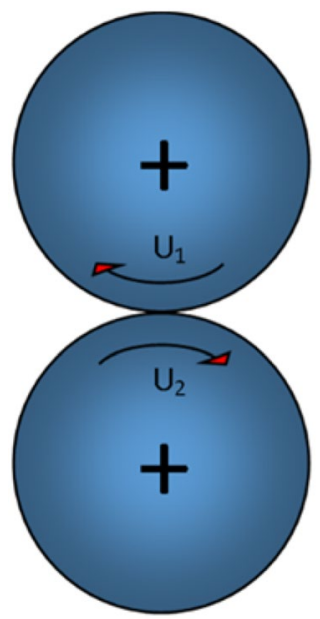

Contra-rotation

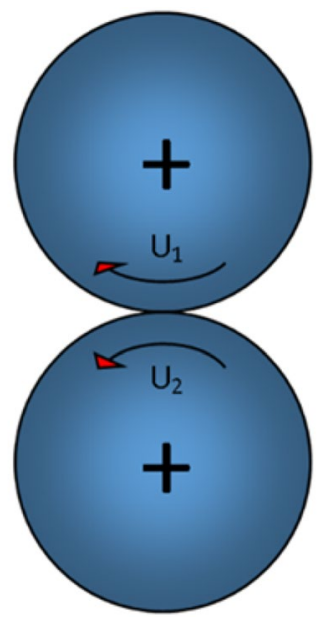

Conventional Method
Fig. 1 An illustration of contra-rotation and conventional (unidirectional) motion during a scuffing test

step in order to allow the specimen bulk temperature to fall back to sump temperature before each test stage. They also employed a step-wise increase in sliding speed rather than load, so that no fresh, unprotected asperities are brought into contact at each step. Ingram et al. [4] demonstrated their method using a selection of base oils. However they identified two problems that needed addressing:

- Firstly, there was a significant variability in the obtained test results.

- Secondly, they suspected that the oil film shape in a counter-rotation contact with zero or very low speed might not follow the standard EHL theory due to formation of a central 'dimple', as previously identified by Guo et al. [27] and Nakahara and Yagi [30] amongst others, and attributed to the existence of a thermal wedge due to opposite velocities of the surfaces. Due to this effect, the increase in SRR could lead to unexpected changes in fluid film thickness, which would, in turn, affect scuffing performance, so that no reliable comparative assessment of lubricant scuffing resistance could be made.

The counter-rotation employed in this study attempts to address these issues as described below.

\subsection{Present Test Method}

The present study uses the PCS MTM ball-on-disc tribometer as was also employed by Ingram et al. [4]. The rig is shown schematically in Fig. 2. The ball and disc are driven by separate motors, which enables contra-rotation to be implemented, as well as reaching a wide range of SRRs, from zero (pure rolling) to infinity (pure contra-rotation). The load is applied through the ball shaft via a stepper motor connected to a load arm. The ball shaft is set at an angle to the disc in order to minimise the spin in the contact. The test specimens are contained inside a temperature-controlled lubricant bath. Friction is measured continuously throughout the test by means of a force transducer attached to the ball shaft, as indicated in Fig. 2. The rig is controlled via a computer equipped with associated software. The conventional MTM can operate at a maximum load of $75 \mathrm{~N}$, corresponding to a maximum contact pressure with the steel specimens used of $1.25 \mathrm{GPa}$. In some of the tests in this study a new version of the MTM, the extreme traction machine (ETM) was used. This can operate at loads up to $1650 \mathrm{~N}$, corresponding to a maximum contact pressure of 3.5 GPa for steel on steel contacts.

The properties and dimensions of the MTM ball and disc specimens are shown in Table 1.

In this study the MTM ball and disc are rotated in opposite direction so as to achieve contra-rotation. In rolling-sliding contacts, the entrainment speed or mean rolling speed $U_{\mathrm{e}}$ is defined by,

$U_{\mathrm{e}}=\frac{u_{\mathrm{ball}}+u_{\mathrm{disc}}}{2}$,

where $u_{\text {ball }}$ and $u_{\text {disc }}$ are the surface speeds of these specimens with respect to the stationary contact. The sliding

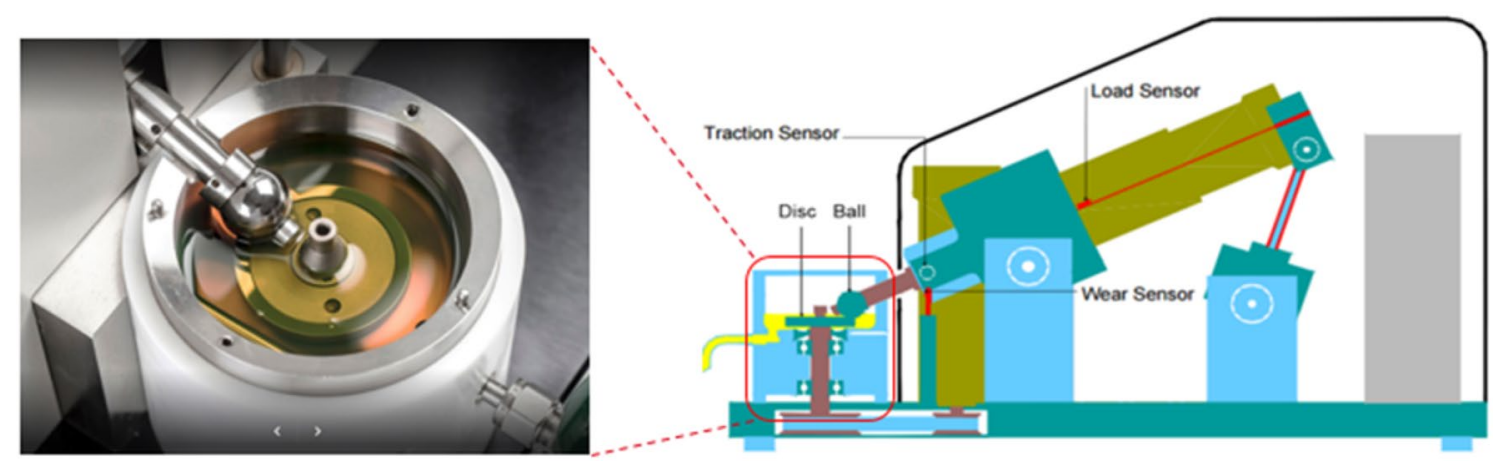

Fig. 2 A schematic diagram of the mini-traction-machine (MTM) [31] 
Table 1 Properties of the MTM ball and disc specimens

\begin{tabular}{lll}
\hline & MTM ball & MTM disc \\
\hline Material & AISI 52100 steel & AISI 52100 steel \\
Elastic modulus (GPa) & 207 & 207 \\
Poisson's ratio & 0.3 & 0.3 \\
Hardness (Hv) & $800 \pm 15$ & $760 \pm 15$ \\
Roughness, Ra (nm) & 12 & 6 \\
Diameter (mm) & 19.05 & 46 \\
\hline
\end{tabular}

speed, $u_{\mathrm{s}}$, is the speed difference between the ball and disc surfaces, i.e.

$u_{\mathrm{s}}=u_{\mathrm{ball}}-u_{\mathrm{disc}}$.

The SRR is the ratio of sliding speed to rolling speed, i.e.

$\mathrm{SRR}=\frac{2\left(u_{\text {ball }}-u_{\text {disc }}\right)}{u_{\text {ball }}+u_{\text {disc }}}$.

When $u_{\text {ball }}$ and $u_{\text {disc }}$ are the same (pure rolling), then $U_{\mathrm{e}}=u_{\text {ball }}=u_{\text {disc }}, u_{\mathrm{s}}=0$ and $\mathrm{SRR}=0$. When the disc is stationary but the ball rotates (sometimes erroneously called "pure sliding") then $U_{\mathrm{e}}=u_{\text {ball }} / 2$ and $u_{\mathrm{s}}=u_{\text {ball }}$ and $\mathrm{SRR}=2$. If both ball and disc rotate in opposite directions at the same speed so that $u_{\text {ball }}=-u_{\mathrm{disc}}$ then $U_{\mathrm{e}}=0$ and the contact is indeed in "pure sliding" and SRR theoretically has the value infinity whatever the sliding speed, which is $2 u_{\text {ball }}$. In the current study a constant, low entrainment speed of normally $U=0.2 \mathrm{~m} / \mathrm{s}$ and sliding speeds in range 0.5 to $4 \mathrm{~m} / \mathrm{s}$ were employed, so the SRRs were in the range 1.5 to 20 (150-2000\%).

\subsubsection{Running-in Procedure}

In an attempt to reduce the variability in the scuffing results in relation to those observed by Ingram et al. [4], the running-in procedure of the specimens was modified. The importance of running-in to scuffing resistance has been addressed by Ludema [19] and, given its importance in tribology, the general mechanisms of the running process have been studied by various authors, e.g. [32, 33]. Given that scuffing can occur suddenly due to small departure from nominal contact conditions on local level, it is generally recognised that small variations in the precise characteristics of surface roughness can have a strong influence on scuffing performance of a surface. The relevant roughness characteristics include the distribution of asperity heights, commonly described through parameters such as root-meansquare roughness $(\sigma)$ and its skewness and kurtosis, but also the spatial characteristics of roughness, often described through correlation length $\left(\beta^{*}\right)$ as derived from the autocorrelation function [34]. For example, Hirst and Hollander [12] identify safe and unsafe regions for sliding of two rough surfaces under boundary lubrication in terms of root-meansquare roughness and correlation length $\left(\sigma-\beta^{*}\right.$ charts). These roughness parameters are known to affect the local contact conditions, including micro-EHL films and friction $[35,36]$, asperity stresses $[37,38]$ and any potential load support afforded by fluid entrapped in surface valleys [39]. Given that scuffing initiates on a local level, apparently small variations in these parameters can have a strong influence on scuffing behaviour of a surface. No two machined surfaces are identical, so that the scuffing performance of two seemingly identical components can be very different depending on the inherent variation in surface roughness. The same is the case for the surfaces of the ball and disc specimens used in the MTM tests despite the fact that they are very tightly controlled. Running-in then offers an opportunity to change the surface microtopography of the fresh specimens through a mild wear process in an attempt to ensure that variation in roughness across specimens is minimised prior to the start of the actual scuffing test.

Ingram et al. [4] used the actual test load with very low sliding and entrainment speeds during the running-in stage. However, close inspection of surfaces run-in in this way in the present study revealed that at higher test loads this approach could produce considerable damage on the surfaces, the level of which was not constant from test to test. To establish the optimum running-in conditions that produce good repeatability in test results, the present investigation tested several combinations of load, sliding speed, entrainment speed and running-in duration for their running-in suitability. Listing all these combinations and the associated observations would be too lengthy for the purposes of this paper, but the general range of parameters covered in the evaluation was load between 20 and $75 \mathrm{~N}$, entrainment speed between 3 and $200 \mathrm{~mm} / \mathrm{s}$, sliding speed between 10 and $300 \mathrm{~mm} / \mathrm{s}$ and running-in duration of up to $600 \mathrm{~s}$. In addition, tests were also done with no running-in at all i.e. specimens were used as supplied. Suitability of the runningin conditions was judged by their ability to reduce the initial variation in friction coefficient measured with different fresh specimen sets, so that the friction at the start of the scuffing test itself is at the same, steady level in all cases. Inadequate running-in conditions were found not to be able to reduce this variation or, in the case of harsher conditions, to rapidly increase friction and to damage the surfaces during the running-in itself. Such conditions were therefore discarded.

Following this detailed exploration, the optimal running-in conditions were found to be a load of $20 \mathrm{~N}$ (Hertz pressure $=0.82 \mathrm{GPa}$ ), a sliding speed of $0.01 \mathrm{~m} / \mathrm{s}$ and an entrainment speed of $3 \mathrm{~mm} / \mathrm{s}$, with a duration of $600 \mathrm{~s}$. In contrast to Ingram et al. [4], the same running-in load was used regardless of the actual scuffing test load; so that the condition of specimen surfaces at the start of a scuffing test was independent of the test conditions employed. 
To illustrate repeatability Fig. 3 presents an example of the friction traces of the running-in process from three separate fresh sets of MTM specimens. It is evident that the friction traces for the three specimens are different at the start of the running-in stage, but that this difference disappears by the end of the running-in process and the friction is at the same, steady value for all specimen sets.

It may intuitively be expected that the optimal runningin conditions would vary for different material-lubricant combinations. However, the running-in conditions used here were found to be suitable for a wide range of material-oil combinations. Tests with a selection of oils are shown later in this paper illustrating this, but further oil formulations as well as diesel fuels were also tested in the course of this research. Similarly, although only the results with AISI 52100 specimens are shown here, the quoted running-in conditions worked just as well with M2 tool steel, nitrocarburised steel and DLC coatings. However, it should be noted that, while the chosen running-in conditions work well over a wide range of material-lubricant combinations, there may be cases where it is necessary to optimise the runningin conditions for specific material-oil combinations.

\subsubsection{Potential Effects of Thermal Wedge in Contra-rotation}

The second issue identified by Ingram et al. [4] as potentially affecting the reliability of their test method is the possible existence of an EHL "dimple" during contra-rotation. This effect has been observed specifically under contra-rotation conditions by Guo et al. [27, 28], Nakahara and Yagi [30] and Meng et al. [26] amongst others. Kaneta et al. [40] was the first to suggest that, instead of the flat film thickness over the central region of the contact, as predicted and normally measured by the conventional EHL theory, under pure sliding conditions a deep conical thick film region (a dimple) may form within the contact. Subsequently, the mechanisms of dimple formation, coupled with the conditions leading to its development inside the contact area, have been widely investigated [28, 41-44].

An attempt was made to identify the conditions under which the dimple effect may be of significance in contrarotation so that the test conditions for the scuffing tests could be chosen to avoid it. This investigation into the formation of a central dimple under contra-rotation conditions is not intended to reveal details of the mechanism of dimple formation but it simply aims to confirm that dimple does not form under the employed scuffing conditions and that therefore, this phenomenon has no effect on the presented results. To achieve this, EHL film shapes were studied in contra-rotation conditions using a ball-on-disc optical interferometry rig (PCS Instruments EHD2). The rig is illustrated schematically in Fig. 4. The applicability of the results to the MTM scuffing tests was ensured by using the same range of oils and the same standard ball specimen as employed in MTM. Using the spacer layer imaging method (SLIM) [45] 3D maps of the EHL film were obtained. Figure 5 shows maps and corresponding 2D profiles of the film thickness measured under pure rolling $(\mathrm{SRR}=0 \%)$ and two contra-rotation conditions with SRR of $400 \%$ and $900 \%$. In this example the entrainment speed is fixed at $500 \mathrm{~mm} / \mathrm{s}$, the test temperature is $30{ }^{\circ} \mathrm{C}$ and the load is $20 \mathrm{~N}$ (Hertz pressure $=0.5 \mathrm{GPa}$ ). It can be observed that in pure rolling conditions $(\mathrm{SRR}=0 \%)$ the classic flat plateau is present in the central film region. As the SRR increases to $200 \%$ at constant entrainment speed, the film thickness reduces somewhat as may be expected due to considerable inlet heating. The contra-rotation region is

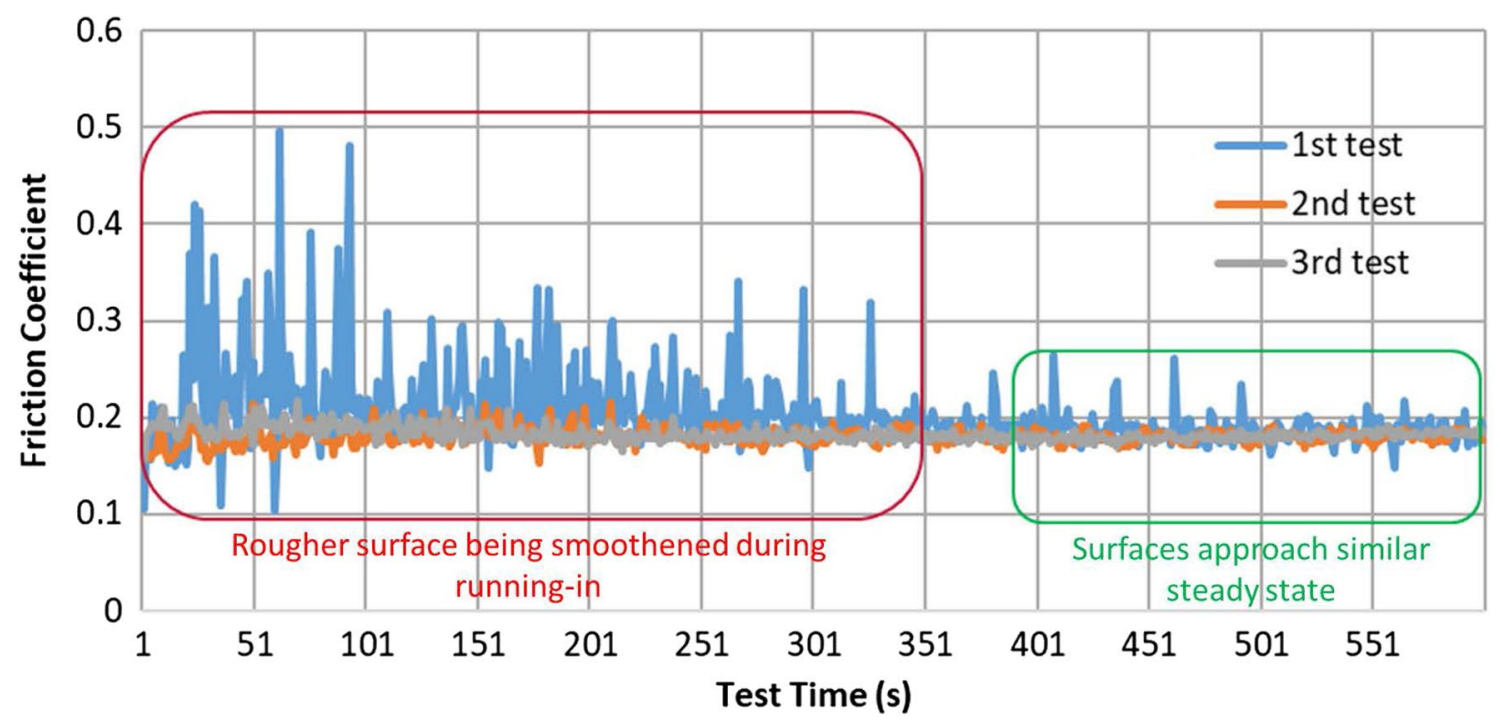

Fig. 3 The friction coefficient recorded during the running-in stage for three different sets of fresh specimens. Tests with Group III base oil 


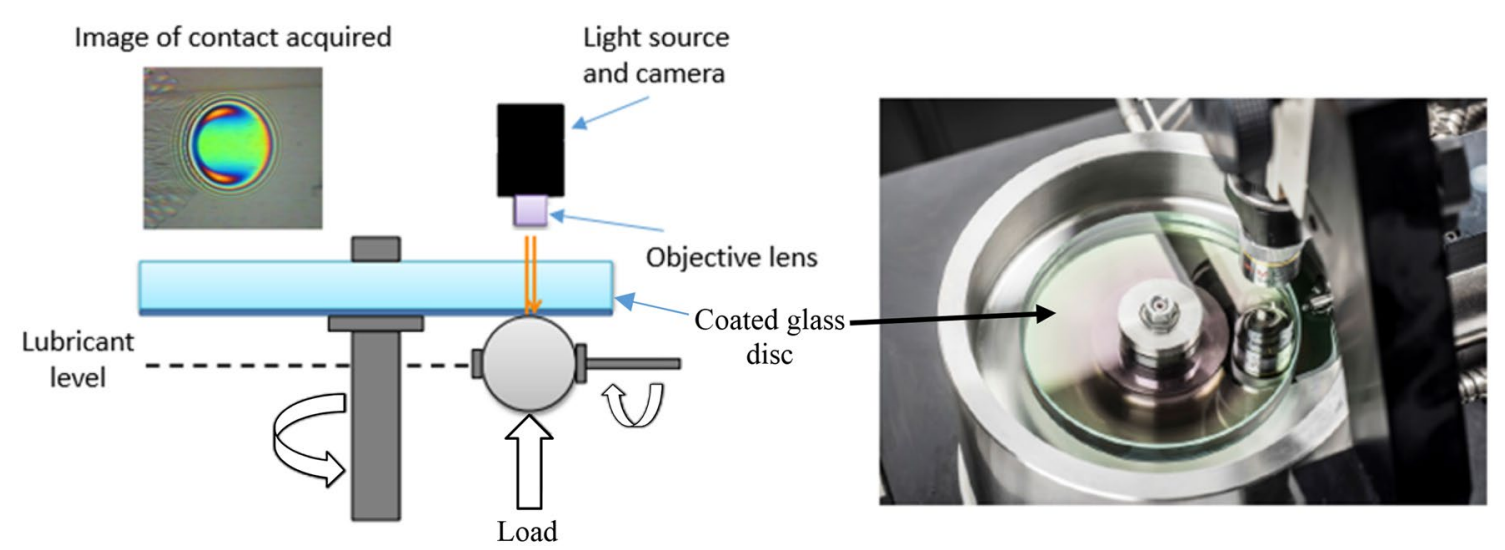

Fig. 4 EHD2 set-up and sample image of the lubricated contact

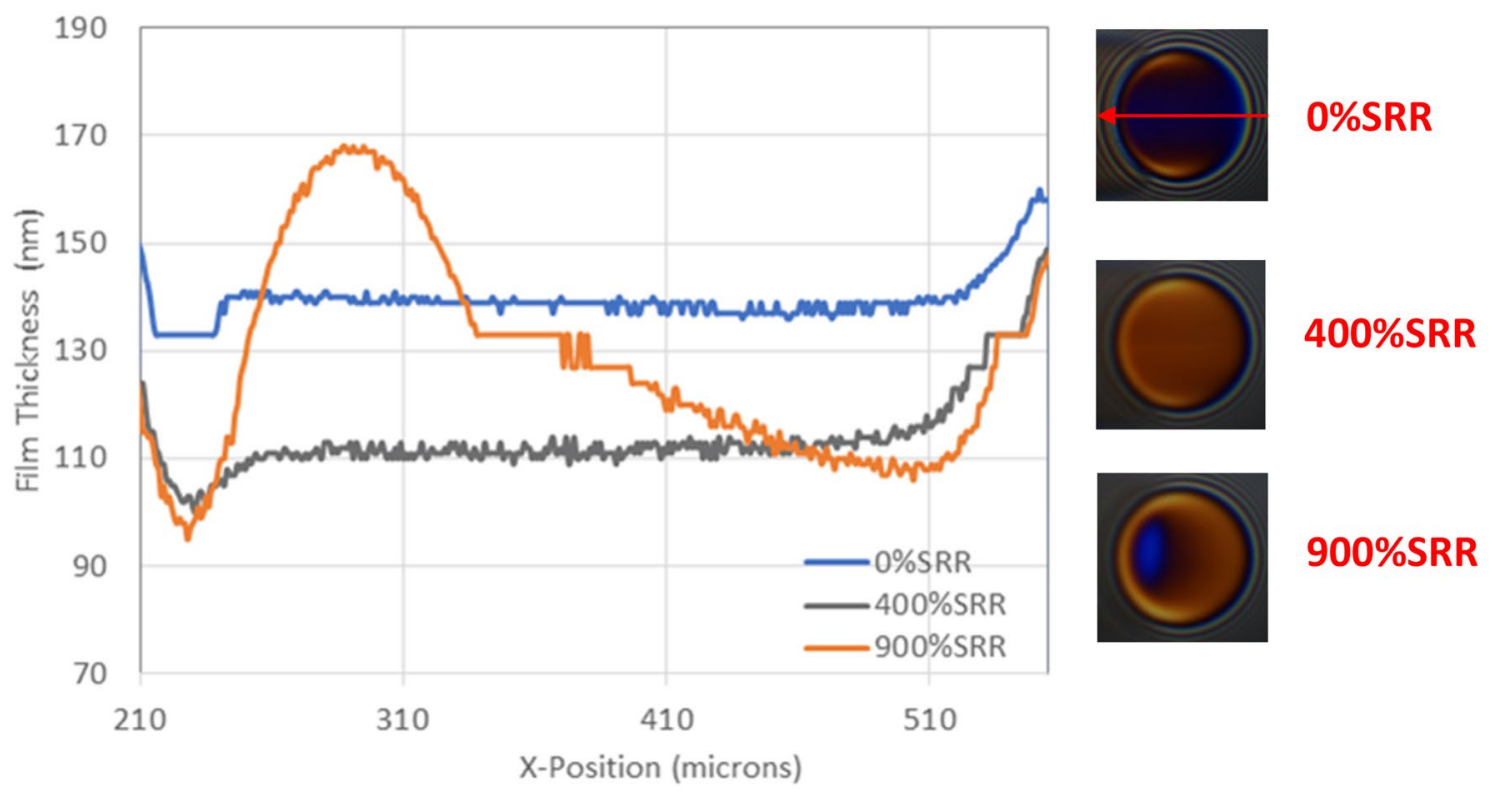

Fig. 5 Film thickness profiles in rolling direction measured on the EHD2 rig at different SRRs. Corresponding SLIM images are shown on the right (entrainment speed $=500 \mathrm{~mm} / \mathrm{s}, 30^{\circ} \mathrm{C}$, load $=20 \mathrm{~N}$, Group IV base oil, $\eta=30 \mathrm{mPa}$ s at $30{ }^{\circ} \mathrm{C}$ )

entered as SRR increases above $200 \%$. At SRR $=400 \%$ it is evident that the central film region is still intact and the film is obeying the EHL theory i.e. contra-rotation itself is insufficient to trigger the dimple effect. As the SRR is increased yet further to $900 \%$, a dimple becomes clearly evident within the central region of the contact but somewhat towards the exit. The dimple is clearly visible in both the plotted 2D film thickness profile and the image of the film map (on the right). The effect of the dimple is to increase the maximum film thickness to more than twice the value in the remainder of the central region, while also decreasing the minimum film value at the exit. The dimple effects appear significant and its potential existence is therefore likely to affect the scuffing performance recorded under the relevant conditions.
To identify the range of the conditions where a dimple may form, further film thickness measurements were performed with two different base oil types (Group III and a Group IV PAO), a range of entrainment speeds and SRRs from 0 to $1500 \%$. The film maps obtained in these tests are summarised in Fig. 6. The two oils have different viscosities, so the test temperatures were adjusted slightly to provide the same viscosity at the test conditions. The load was $20 \mathrm{~N}$ in all cases. For the range of SRR tested, no dimple occurred at all at an entrainment speed of $200 \mathrm{~mm} / \mathrm{s}$, in fact the specimens appeared to scuff above SRR $=1400 \%$ for both oils. At the higher entrainment speeds of $400 \mathrm{~mm} / \mathrm{s}$ and $600 \mathrm{~mm} / \mathrm{s} \mathrm{a}$ dimple was observed at a similar SRR for both oils, around $1000 \%$ and $700 \%$ respectively for the two entrainment 


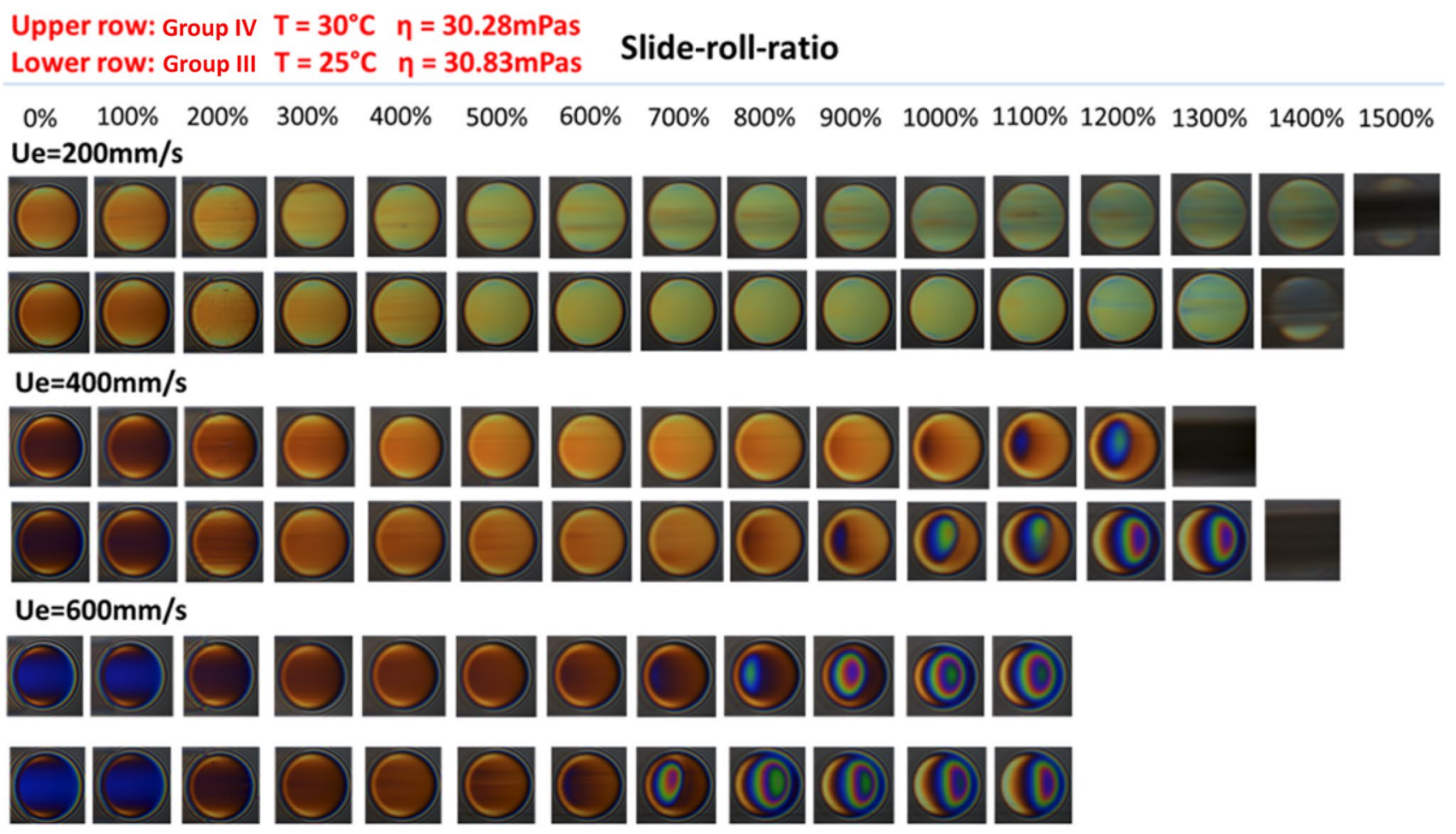

Fig. 6 SLIM images of the ball-on-disc contact for two base oils at different entrainment speeds and SRRs. Load is $20 \mathrm{~N}$ in all cases

speeds. The results suggest that base oil type does not influence the occurrence of the dimple effect. A dimple forms at a lower SRR when a higher entrainment speed is present i.e. its occurrence is governed by the contact sliding speed. In fact, considering the values of SRR and entrainment speeds, the formation of the dimple was only observed above a sliding speed of $4 \mathrm{~m} / \mathrm{s}$ for both oils. Therefore, if the scuffing test conditions are kept below this sliding speed, any potential effects of the dimple can be excluded, ensuring the validity of the recorded scuffing results.

\subsubsection{Test Procedure for the Contra-rotation Scuffing Test}

Having addressed the potential issues with the running-in procedure and any effects of a 'dimple', the complete test procedure for the present scuffing test can now be outlined. The procedure consists of three stages as shown in the flowchart of Fig. 7. The first of these is a running-in stage. Following the results of the investigation into the optimal running-in conditions, this step is performed for $600 \mathrm{~s}$, at a load of $20 \mathrm{~N}$, an entrainment speed of $3 \mathrm{~mm} / \mathrm{s}$, a sliding speed of $10 \mathrm{~mm} / \mathrm{s}$ and the same temperature as that used for the testing stage. This is followed by a series of test steps, where the entrainment speed and load are held constant and the sliding speed is increased in steps of $0.1 \mathrm{~m} / \mathrm{s}$. Between each of these test steps, a $30 \mathrm{~s}$ rest stage is introduced in order to allow the specimens' bulk temperatures to return back to that of the oil bath. The conditions for each of these steps are outlined in Table 2. The justification behind the chosen conditions for the 'test' and 'rest' stages is now provided.

The test stages are conducted at a fixed value of contact load and entrainment speed. Each test step lasts $30 \mathrm{~s}$. This duration was chosen as appropriate after some trials. Scuffing occurs very quickly once the required conditions are reached, so that $30 \mathrm{~s}$ is sufficiently long to assess the scuffing performance of the oil at the given conditions. Indeed, the test results show that scuffing always occurs in the first few seconds of the step once the required sliding speed is reached. At the same time, the 30 s duration of each step means that no appreciable wear occurs on the surfaces

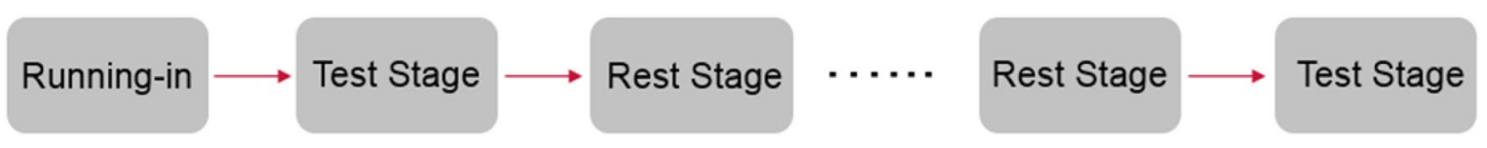

Fig. 7 Flowchart of the scuffing test procedure showing the three stages used 
Table 2 Conditions for running-in and each of the test and rest stages in the present scuffing test procedure

\begin{tabular}{llll}
\hline & Running-in & Test stage & Rest stage \\
\hline Sliding speed $(\mathrm{m} / \mathrm{s})$ & 0.01 & Increasing in steps of $0.1 \mathrm{~m} / \mathrm{s}$ & 30 s MTM mapper step to observe boundary film \\
Entrainment speed $(\mathrm{m} / \mathrm{s})$ & 0.003 & Fixed (to give $\lambda=1$ at the start of step) & \\
Duration $(\mathrm{s})$ & 600 & 30 \\
Load $(\mathrm{N})$ & 20 & $\begin{array}{l}\text { Fixed }(20,40 \text { and } 75 \mathrm{~N} \text { used in the present } \\
\text { study to provide } P V \text { charts) }\end{array}$ \\
Temperature $\left({ }^{\circ} \mathrm{C}\right)$ & 120 & Fixed & \\
\hline
\end{tabular}

during any one test step so that the surface conditions remain the same throughout the test duration, which improves test repeatability and helps to accurately define the conditions at the onset of scuffing. The test entrainment speed for all steps is fixed. In his original study Blok [29] suggested the use of pure contra-rotation in which the two surfaces move in opposite directions at exactly the same speed so that the entrainment speed is zero. However, as pointed out by Ingram et al. [4], zero entrainment speed is difficult if not impossible to achieve precisely and tiny differences in speed close to zero might produce large differences in performance. Therefore, a finite but small entrainment speed was employed in this study, with the two surfaces moving at slightly different speeds in opposite directions. The exact value of this low entrainment speed can be chosen to suit the oils tested. In the present study, $200 \mathrm{~mm} / \mathrm{s}$ was chosen as a suitable value for two reasons: (i) the study on the formation of the 'dimple' showed that at such low entrainment speed the SRR which can be imposed before any dimple effects occur is very high (over $1500 \%$, sliding speed over $4 \mathrm{~m} / \mathrm{s}$ ), so that repeatable scuffing results can be achieved while avoiding the complicating effects of dimple formation, (ii) this entrainment speed achieves the desired initial specific film thickness, or $\lambda$ ratio (= minimum film thickness/RMS roughness) equal to 1 with the oils used in the present study at the chosen test temperature of $120{ }^{\circ} \mathrm{C}$. This film thickness ensures that the tests start in the mixed lubrication regime. For different viscosity oils, the combination of test temperature and entrainment speed can be changed to keep the same initial $\lambda$ ratio while still avoiding the dimple effect.

The purpose of the rest stage is to eliminate any potential effects of frictional heating on the specimen bulk temperatures, which would affect the film thickness at the start of each test step. Given the inevitably high sliding speeds needed to induce scuffing, frictional heating effects in all conventional scuffing tests are significant and make it difficult to define the exact contact conditions at the onset of scuffing. Another benefit of the rest stage is that it helps to clear any debris which may be trapped or accumulated in the contact zone during the test stages, which itself has been observed to be able to cause scuffing [13]. The 'rest' stage is therefore an important part of the procedure to ensure that the conditions at the onset of scuffing are trackable. Ingram et al. [4] employed a $30 \mathrm{~s}$ rest stage during which pure rolling motion was imposed in the ball-disc contact. The current study implements a small modification to this by employing the MTM 'mapper' measurement to serve as the rest stage. The MTM mapper step automatically acquires a colour optical interference image of the ball surface from which a map of any boundary film thickness developed on the ball during testing is then obtained. This procedure employs the SLIM [45] by unloading the ball from the disc and loading it against a glass flat under stationary contact in order to acquire a colour image (see Fig. 8). This is done automatically by the MTM control software, so the test chamber does not need to be opened or the specimens removed at any stage. This 'mapper' procedure also lasts $30 \mathrm{~s}$ during which the disc is slowly rotating in the oil bath, so that the same effect of dropping the specimen temperature to that of the oil bath value is achieved as in the pure rolling condition utilised by Ingram et al. However, the extra information obtained on the development of any boundary film on the ball is useful as it allows for the mechanism of scuffing to be studied, given that scuffing is strongly influenced by the strength of any such film.

Figure 9 presents an example of the data gathered during the scuffing test described above. The friction trace recorded

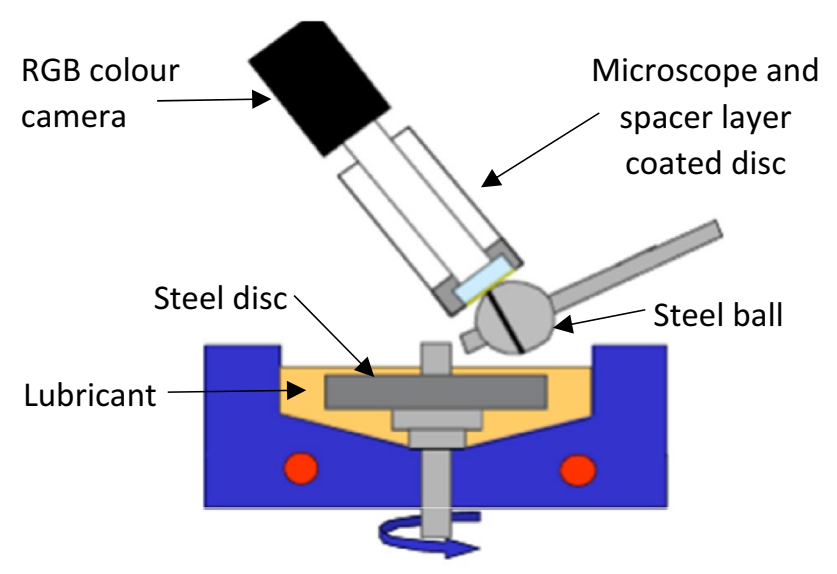

Fig. 8 Schematic representation of MTM-SLIM set-up [31] 
during the running-in stage and also the rest stages are omitted for clarity. It is seen that the friction coefficient remains quite constant up to a sliding speed of $1.3 \mathrm{~m} / \mathrm{s}$. At $1.4 \mathrm{~m} / \mathrm{s}$ some fluctuations in the friction coefficient start to occur, where the friction increases for very short duration, but then drops back down to the nominal steady state value. This behaviour is symptomatic of localised scuffing occurring in selected regions of the contact, i.e. "micro-scuffing", as reported in the literature [17], but whose spread to the rest of the contact is arrested by the action of the lubricant. Such behaviour is particularly common with fully-formulated oils, where extreme pressure (EP) additives may be activated by the temporary increase in friction and hence in contact temperature. When the sliding speed reaches $1.7 \mathrm{~m} / \mathrm{s}$, a very large and unrecoverable increase in friction is seen. It is this event that is used to define scuffing failure in the present test method. More precisely, scuffing is defined as a sharp increase in friction coefficient to above 0.2 and lasting for more than $5 \mathrm{~s}$. The second part of this scuffing definition is important in order to deal adequately with the 'microscuffing' events described above, which could result in the oil being condemned prematurely before the additive package has been given a chance to act. The onset of scuffing is also accompanied by significantly increased noise and rig vibrations, so that it is not possible to miss it.

\section{Oils Used in the Present Study}

The described test procedure was used to test the scuffing performance of a selection of oils. Since the primary practical use of a scuffing test is to rank the scuffing resistance of lubricating oils, three different groups of oils were chosen here in order to illustrate the wide applicability and usefulness of the method, and to compare the observed trends to those obtained in other scuffing tests for the same oils. The first group consists of four model oils with a known formulation. Three of these were unformulated base oils of Group I, III and IV. The fourth one was the same Group I base oil but with a sulphurised isobutylene EP additive blended at a concentration of sulphur of $1 \mathrm{wt} \%$, which would be expected to enhance its scuffing resistance. The tests with these model oils serve three purposes: (i) they asses the influence of the base oil type on scuffing resistance while avoiding effects of unknown additive packages as present in commercial oils, (ii) they allow the repeatability of the present scuffing test to be compared to that of Ingram et al. [4] test who used a similar selection of 'pure' base oils and (iii) the comparison of the relative performance of the Group I and the Group $\mathrm{I}+1 \mathrm{wt} \% \mathrm{~S}$ oils allows for the influence of a sulphur additive to be assessed. The four model oils have similar viscosity at the chosen test temperature so that the same initial specific film thickness was present in all cases without the need to adjust test temperature. Properties of these four oils and the employed test conditions are listed in Table 3.

Although useful for the purposes of test development, base oil test results are of limited practical relevance. For this reason, two groups of fully-formulated oils used in applications where anti-scuffing performance is important were also tested. The first group consists of three fully-formulated light-duty industrial oils which are commonly used in transmission applications where scuffing is generally an important failure mode. The properties of these three oils are listed in Table 4. Their viscosities differ but they are all

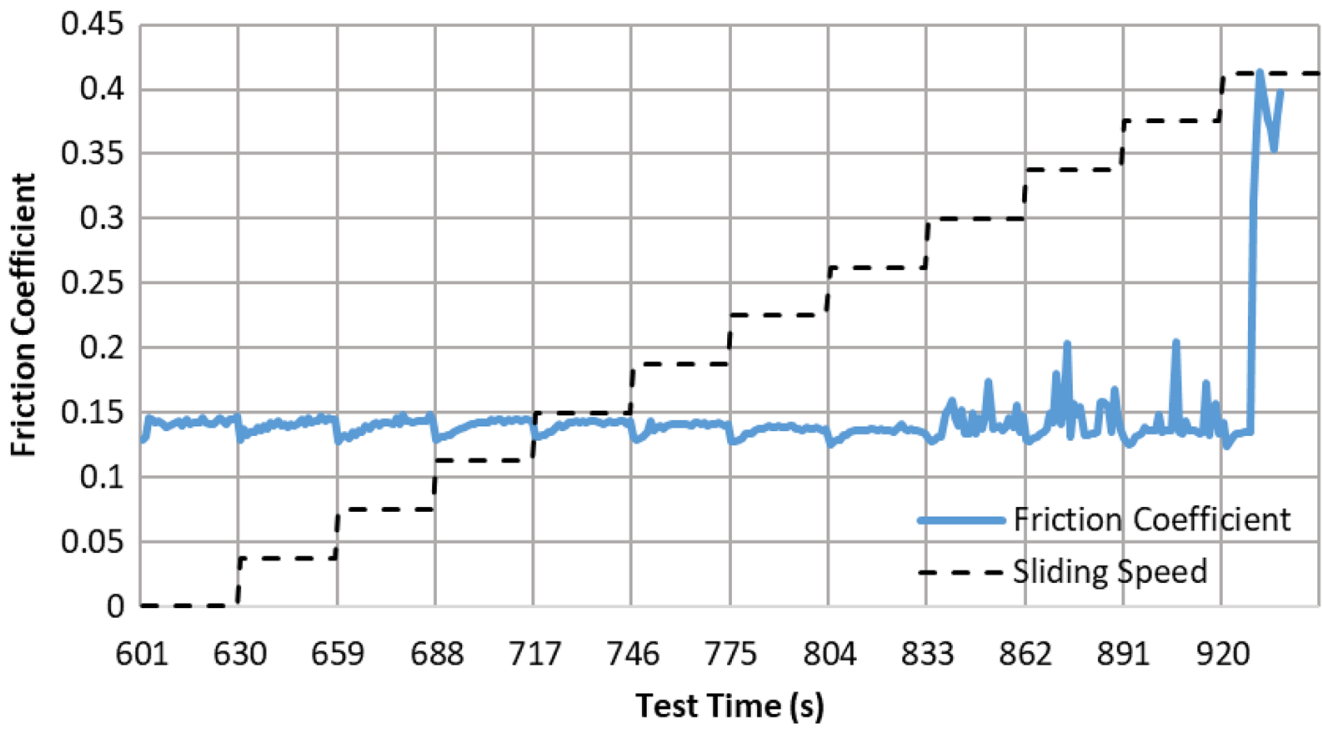

1800

1600

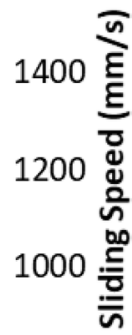

800

600

Fig. 9 The friction coefficient recorded during a scuffing test using a Group III base oil (the figure only contains the test stage data, the friction data from the running-in stage and rest stages are excluded) 
Table 3 Properties of the base oils used in the present study and the associated test conditions employed

\begin{tabular}{llllll}
\hline Base oil & Sulphur content & $\begin{array}{l}\text { Test tem- } \\
\text { perature } \\
\left({ }^{\circ} \mathrm{C}\right)\end{array}$ & $\begin{array}{l}\text { Viscosity at test } \\
\text { temperature }(\mathrm{cP})\end{array}$ & $\begin{array}{l}\text { Entrainment } \\
\text { speed (mm/s) }\end{array}$ & $\begin{array}{l}\text { Film thickness at } \\
\text { test conditions }(\mathrm{nm})\end{array}$ \\
\hline $\begin{array}{l}\text { Group I (+ sul- } \\
\text { phurised isobu- }\end{array}$ & $1 \mathrm{wt} \%$ & 120 & 3.5 & 200 & 13 \\
$\begin{array}{c}\text { tylene) } \\
\text { Group I base oil }\end{array}$ & $0.25 \mathrm{wt} \%$ & 120 & 3.5 & 200 & 13 \\
Group III base oil & $<5 \mathrm{ppm}$ & 120 & 3.0 & 200 & 12 \\
Group IV base oil & $\sim 0$ & 120 & 2.9 & 200 & 12 \\
\hline
\end{tabular}

Table 4 Properties of the three fully-formulated industrial oils used in the present study and the test conditions employed

\begin{tabular}{llllll}
\hline $\begin{array}{l}\text { Industrial } \\
\text { oils }\end{array}$ & $\begin{array}{l}\text { FZG fail } \\
\text { stage } \\
(\mathrm{A} / 8.3 / 90)\end{array}$ & $\begin{array}{l}\text { Test tem- } \\
\text { perature } \\
\left({ }^{\circ} \mathrm{C}\right)\end{array}$ & $\begin{array}{l}\text { Viscosity } \\
\text { at test } \\
\text { tempera- } \\
\text { ture }(\mathrm{cP})\end{array}$ & $\begin{array}{l}\text { Entrain- } \\
\text { ment } \\
\text { speed } \\
(\mathrm{mm} / \mathrm{s})\end{array}$ & $\begin{array}{l}\text { Film thick- } \\
\text { ness at test } \\
\text { conditions } \\
(\mathrm{nm})\end{array}$ \\
\hline Oil A & 8 & 120 & 3.0 & 200 & 12 \\
Oil B & 10 & 120 & 4.6 & 100 & 13 \\
Oil C & 12 & 120 & 5.8 & 80 & 12 \\
\hline
\end{tabular}

from the same series of a single manufacturer and likely to have similar additive packages. The FZG scuffing test data are available for these oils and is also included in Table 4. To ensure that the effect of the viscosity difference is excluded from the test ranking, different rolling speeds (all below $200 \mathrm{~mm} / \mathrm{s}$ to exclude 'dimple' effects) were used for each oil in order to ensure the same specific film thickness of $\lambda=1$ at the start of each test step, as explained above.

The second group of fully-formulated oils consists of two aviation turbine oils. These are designed for use in traditional turbo-fan aircraft engines but are also expected to provide satisfactory scuffing performance in the latest designs of aircraft engines which utilise a geared turbo-fan where scuffing resistance is of importance. Formulation of oils for this specific application is an active area of research so that these results are of practical significance. The properties of the turbine oils and the employed test conditions are shown in Table 5. Their known minimum scuffing resistance, in terms of the minimum Ryder gear load carrying ability as per the MIL-PRF-23699G standard, is also shown in the table. Both are ester-based oils with the same viscosity so that any difference in scuffing performance is due to their chemical composition. These properties make them particularly suitable for the current test. The same test procedure as before, i.e. test temperature of $120{ }^{\circ} \mathrm{C}$ and entrainment speed of $200 \mathrm{~mm} / \mathrm{s}$, was used for these tests too. This results in the specific film thickness value of $\lambda=1$ at the start of each test stage.

The inclusion of these two oil groups serves to test the ability of the present method to successfully scuff fullyformulated oils with enhanced scuffing resistance, while
Table 5 Properties of the two fully-formulated aviation turbine oils used in the present study and the test conditions employed

\begin{tabular}{llllll}
\hline $\begin{array}{l}\text { Aviation } \\
\text { turbine } \\
\text { oils }\end{array}$ & $\begin{array}{l}\text { Min } \\
\text { Ryder } \\
\text { gear load } \\
\text { carrying } \\
\text { ability (as } \\
\text { per MIL- }\end{array}$ & $\begin{array}{l}\text { Viscosity } \\
\text { at } 10{ }^{\circ} \mathrm{C}\end{array}$ & $\begin{array}{l}\text { Test tem- } \\
\text { perature } \\
\left({ }^{\circ} \mathrm{C}\right)\end{array}$ & $\begin{array}{l}\text { Entrain- } \\
\text { ment } \\
\text { speed } \\
(\mathrm{mm} / \mathrm{s})\end{array}$ & $\begin{array}{l}\text { Film thick- } \\
\text { ness at test } \\
\text { conditions } \\
(\mathrm{nm})\end{array}$ \\
& $\begin{array}{l}\text { PRF- } \\
\text { 23699G) } \\
(\%)\end{array}$ & & & & \\
\hline $\begin{array}{c}\text { Turbine } \\
\text { oil 1 }\end{array}$ & 102 & 5 & 120 & 200 & 12 \\
$\begin{array}{c}\text { Turbine } \\
\text { oil 2 }\end{array}$ & 110 & 5 & 120 & 200 & 12 \\
\hline
\end{tabular}

the availability of the FZG and Ryder gear test data makes it possible to compare the trends obtained here to those recorded in these established scuffing tests.

\section{Experimental Results}

This section presents the scuffing results obtained using the present contra-rotation method. The results with the base and model oils are presented first, followed by those for the fully-formulated industrial oils. Finally, the application of the method at higher pressures using the newly developed high load MTM rig (ETM) is demonstrated.

\subsection{Base Oil Tests}

The described test method was first used to assess the scuffing resistance of the four base oils listed in Table 3. The tests were performed at three different loads, $20 \mathrm{~N}, 40 \mathrm{~N}$ and $75 \mathrm{~N}$ corresponding to maximum Hertz pressures of $0.82 \mathrm{GPa}, 1.03 \mathrm{GPa}$ and $1.25 \mathrm{GPa}$. This approach makes it possible to compare the performance of the oils through $P V$ charts which identify the safe and unsafe regions in terms of scuffing onset. Three repeats were done at each load other than for the EP containing oil, where two repeat tests were performed. Figure 10 shows the recorded friction for the 
four oils at each of the three loads. A number of observations can be made here. Firstly, in all cases the onset of scuffing is clearly identified by a rapid and unrecoverable increase in friction. The corresponding sliding speeds at the point of scuffing for all tests are listed in Table 6. Good repeatability is shown for tests with all oils, with scuffing speeds in repeated tests at each load being relatively close. The increase in friction at the onset of scuffing is much more rapid, almost instantaneous, for the Groups III and IV base oils than for Group I and particularly Group I+EP additive oil. In the case of the latter two oils, the friction traces are much less smooth, with frequent jumps followed by recovery back to the nominal level, prior to the onset of scuffing. This suggests that some local scuffing may be occurring during this period but the sulphur content of these two oils appears able to arrest the spread of damage and hence postpone scuffing failure to higher sliding speeds. The link between the boundary films and scuffing propensity is clearly illustrated in the SLIM images of Fig. 11. In Fig. 11b it is evident that boundary films are formed by the Group $\mathrm{I}+\mathrm{EP}$ additive oils in the early stages of the test, indicated by the changing colours in the interferometry images, presumably due to the action of sulphur. These films are then seen to be progressively destroyed during the few steps preceding scuffing, accompanied by the gradual increase in friction as more and more bare metal surface is exposed, to almost totally disappear just prior to the onset of scuffing. The SLIM image taken immediately after the occurrence of scuffing clearly shows that the surface of the ball has been significantly damaged. This behaviour appears to confirm that the mechanism of scuffing in the case of additivised oils is controlled by the strength of the boundary film. In contrast, the SLIM images for the Group I base oil shown in Fig. 11a do not show evidence of any significant boundary film formation in the early stages of the test, suggesting that
Fig. 10 Friction data recorded during the scuffing tests with four base oils at three different loads
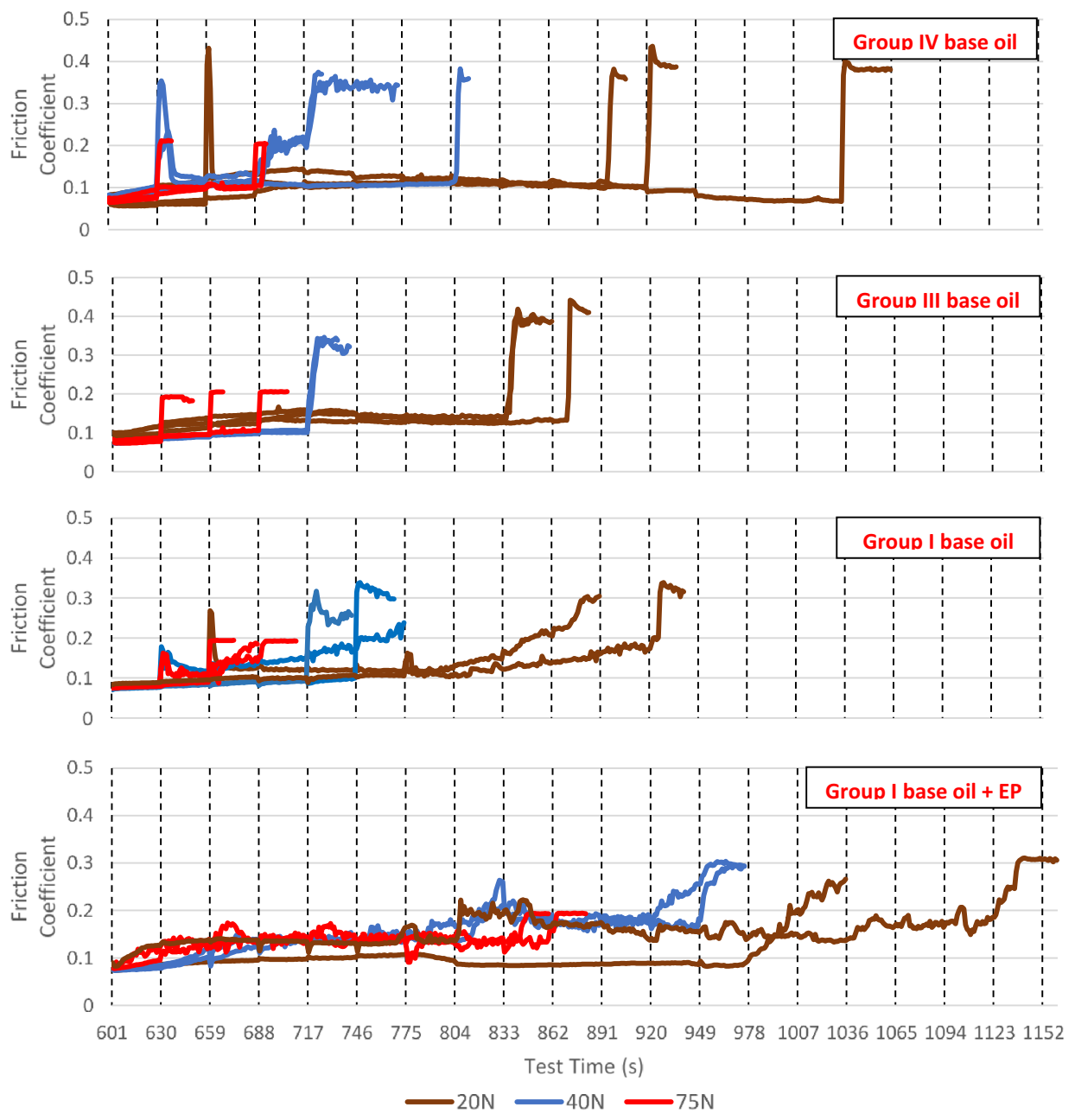

\begin{tabular}{|l|l|l|l|l|l|l|l|l|l|l|l|l|l|l|l|l|l|l|}
\hline 0.6 & 0.7 & 0.8 & 0.9 & 1.0 & 1.1 & 1.2 & 1.3 & 1.4 & 1.5 & 1.6 & 1.7 & 1.8 & 1.9 & 2.0 & 2.1 & 2.2 & 2.3 & 2.4 \\
\hline
\end{tabular}

Sliding Speed (m/s) 
Fig. 11 Example SLIM images captured during the scuffing test; a Group I base oil with $1 \mathrm{wt} \% \mathrm{~S}$ and b Group I oil. All at $20 \mathrm{~N}$ contact load
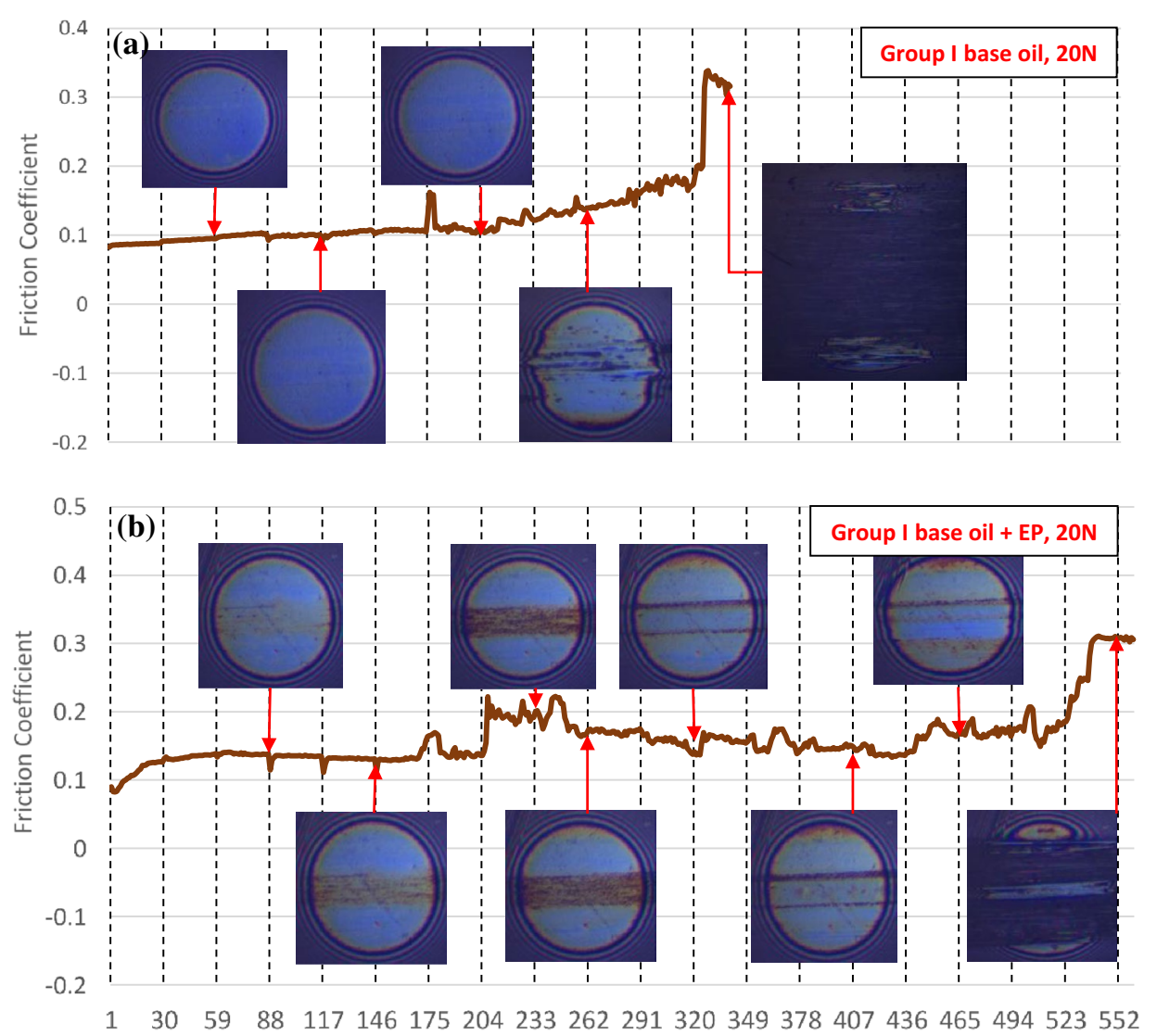

Test Time (s)

\begin{tabular}{|l|l|l|l|l|l|l|l|l|l|l|l|l|l|l|l|l|l|l|}
\hline 0.6 & 0.7 & 0.8 & 0.9 & 1.0 & 1.1 & 1.2 & 1.3 & 1.4 & 1.5 & 1.6 & 1.7 & 1.8 & 1.9 & 2.0 & 2.1 & 2.2 & 2.3 & 2.4 \\
\hline
\end{tabular}

Sliding Speed $(\mathrm{m} / \mathrm{s})$

\begin{tabular}{|c|c|c|c|c|c|c|c|c|c|c|c|c|}
\hline \multirow{2}{*}{$\begin{array}{l}\text { Load (N) } \\
20\end{array}$} & \multirow{2}{*}{$\begin{array}{l}\text { Pressure (GPa) } \\
0.82\end{array}$} & \multicolumn{3}{|c|}{ Group IV base oil } & \multicolumn{3}{|c|}{ Group III base oil } & \multicolumn{3}{|c|}{ Group I base oil } & \multicolumn{2}{|c|}{$\begin{array}{l}\text { Group I+ } 1 \% \\
\mathrm{~S}\end{array}$} \\
\hline & & 1.7 & 1.6 & 2.1 & 1.4 & 1.4 & 1.8 & 1.5 & 1.7 & 1.8 & 2.4 & 2 \\
\hline 40 & 1.03 & 1 & 1.3 & 1 & 1 & 1 & 1 & 1.2 & 1.1 & 1 & 1.8 & 1.8 \\
\hline 75 & 1.25 & 0.9 & 0.7 & 0.9 & 0.7 & 0.8 & 0.9 & 0.8 & 0.8 & 0.9 & 1.4 & 1.4 \\
\hline
\end{tabular}

Table 6 Recorded sliding speeds at scuffing point for the four base oils tested are also visible. These are all generally considered to be characteristic of scuffing damage in real components such as gears and cams, indicating that the present test can successfully reproduce the phenomena.

To better illustrate the relative differences in the scuffing performance of these four oils, Fig. 13 plots the obtained results on the load versus sliding speed graph (a $P V$ chart). For each of the oils, the regions above the plotted line contain the $P V$ values where scuffing is likely to occur and those below the line are scuffing safe regions. The plotted scuffing speed is the average of all test repeats at a given condition shown in Table 6. The error bars 

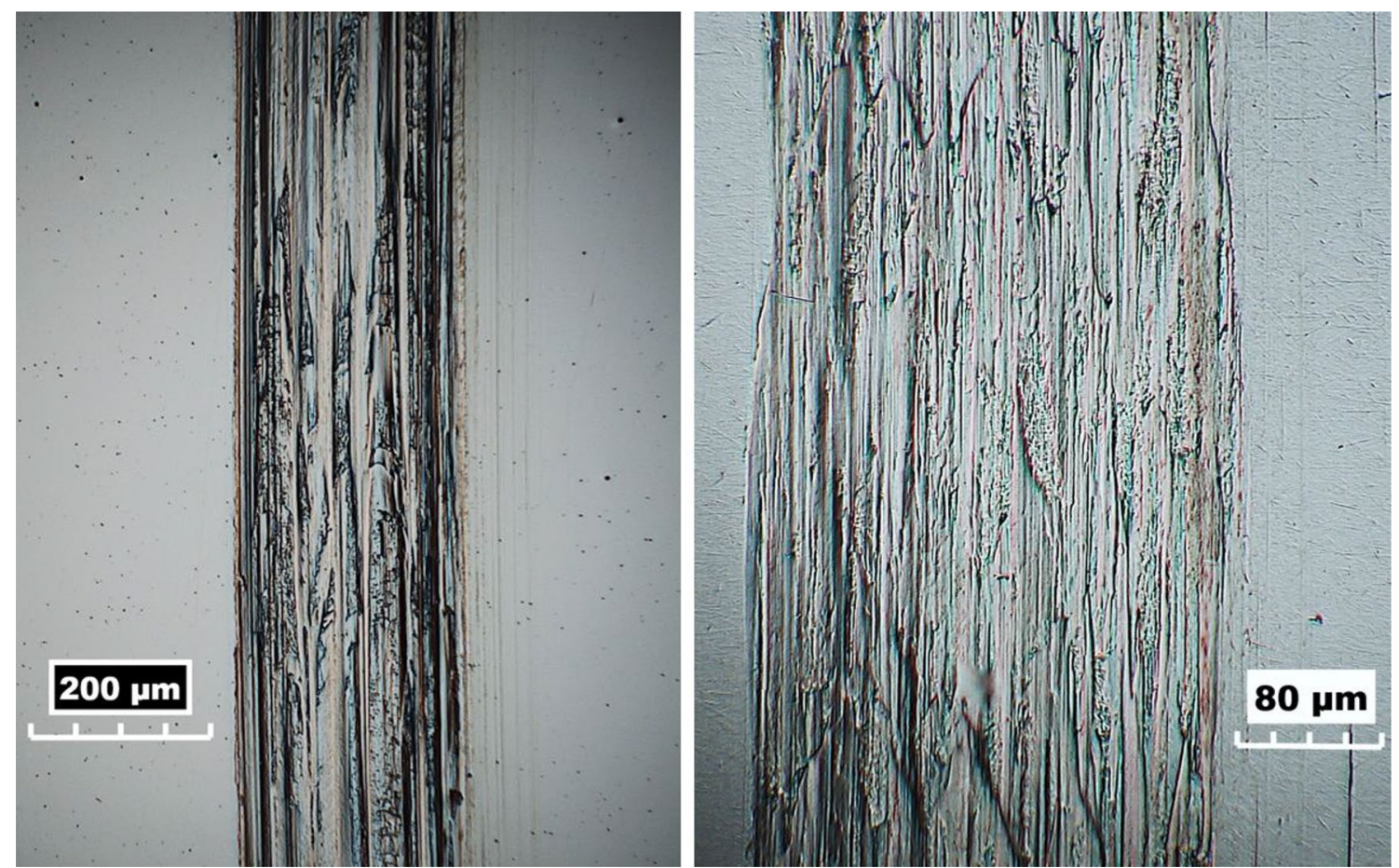

Fig. 12 Example images of scuffing damage on the disc (left) and ball (right). Test with Group IV base oil at $20 \mathrm{~N}$ (for comparison, contact diameter is $215 \mu \mathrm{m})$

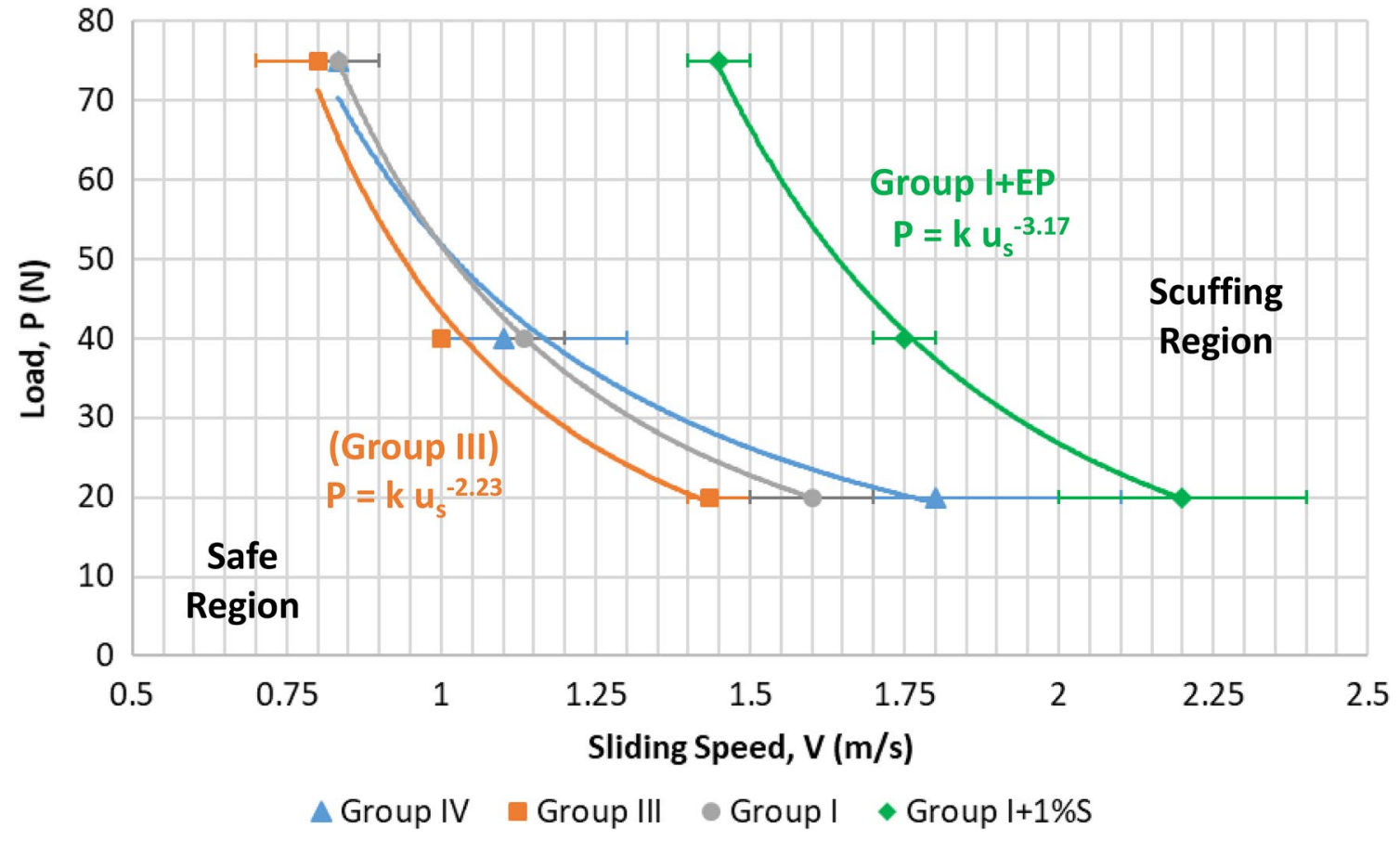

Fig. $13 P V$ transition chart for scuffing failure for four model oils listed in Table 3 
(based on the maximum and minimum values) are added to indicate the variability in the scuffing speed data.

The three 'pure' base oils generally show similar scuffing resistance. Although, at low pressures the Group IV oil appears to have a slightly better performance on average than Group I and III oils, the differences are contained within the error bars, so it is unlikely that this is of significance. Ingram et al. [4] observed that PAO oil provided considerably better scuffing protection than Group I and III base oils under mixed lubrication conditions over the whole load range tested. The result was unexpected, given the negligible sulphur content of the PAO oil, and was attributed to potential differences between the oils in terms of the 'dimple' mechanism, and possibly the fact that the running-in procedure employed did not allow sufficient time for the boundary films to form with the sulphur containing Group I oil. In the present tests, the effect of the dimple was shown not to be present at the employed conditions, while the runningin procedure was also modified. Therefore, these changes may be responsible for different observations in the relative performance of the PAO oil. It is not entirely clear why the Group I oil, which contains $0.25 \mathrm{wt} \%$ sulphur, fails to provide any improvement over Group III and IV oils, although the SLIM images of Fig. 11 suggest that despite its sulphur content, this oil is unable to build significant boundary films under the tested conditions, just like the 'pure' Group III and IV oils, so that similar scuffing performance may be expected.

In contrast, it is clearly evident in Fig. 13 that Group I $+1 \mathrm{wt} \%$ sulphur oil exhibits a significantly better scuffing performance than 'pure' base oils, with a scuffing speed increase of around $40 \%$ throughout the range of loads tested. This is to be expected given the ability of sulphur to quickly react with exposed metal surfaces to form a protective sulphide layer and hence postpone the onset of scuffing. This mechanism is supported by the SLIM images of Fig. 11, where the presence of a boundary film for this oil was clearly evident.

The shape of the curves in Fig. 13 is indicative of a power law relationship,

$P u_{\mathrm{s}}{ }^{n}=$ constant,

where $P$ is the load and $u_{\mathrm{s}}$ is the sliding speed.

This is in line with the generally accepted relationship between pressure and sliding speed at scuffing. The value of the sliding speed exponent, $n$, lies in the narrow range of 1.7 to 2.2 for the 'pure' base oils, while it is 3.17 for the Group $\mathrm{I}+\mathrm{EP}$ oil, again indicating that an additional mechanism is at play in the latter case.

\subsection{Tests with Light-Duty Industrial Oils}

Scuffing tests were conducted with three fully-formulated commercial oils, the properties of which are listed in Table 4. These tests examine the ability of the present method to produce scuffing with oils that contain a full additive package and should therefore have a superior scuffing performance to the base oils tested above. In addition, the FZG scuffing test data were available for these oils so that it is possible to compare the general trends in scuffing resistance evident in that data to those obtained here.

Figure 14 shows the friction traces recorded during the scuffing tests with the three oils at loads $20 \mathrm{~N}, 40 \mathrm{~N}$ and 75 N. Scuffing was achieved with all three oils and loads, as indicated by the permanent increase in friction apparent in the graphs. Prior to the onset of scuffing, the friction traces for all three oils show oscillations similar to those observed with the Group I+ $1 \%$ sulphur oil. This supports the suggestion that the EP additives act very quickly when friction increases to delay the final scuffing failure. These results are plotted on a $P V$ chart in Fig. 15. It is immediately apparent that the scuffing performance of all three oils is very similar. The speed exponent in $P V^{n}=$ constant is about 1.8 in all three cases. The similarity between the three oils is perhaps unsurprising given that all come from the same product series so are likely to have the same additive package, and the present test is designed to test the effectiveness of this additive package to prevent scuffing while excluding the influence of oil viscosity. The FZG scuffing loads for the three oils are different, namely load stage 8,10,12 for oil $\mathrm{A}, \mathrm{B}$ and $\mathrm{C}$ respectively. The viscosity of the oils increases in the same order (see Table 4), so that this ranking is to be expected on the FZG test which does not differentiate between viscosity and additive effects on scuffing performance: higher viscosity oils will produce higher EHL film thickness, and hence a better scuffing performance in the FZG test but not with the present method.

\subsection{Tests with Aviation Turbine Oils}

Figure 16 shows the recorded friction traces during scuffing tests with the two aviation turbine oils. Results are shown at loads of $20 \mathrm{~N}, 40 \mathrm{~N}$ and $75 \mathrm{~N}$. It is apparent that the repeatability of the results is very good, with all three repeats at each load scuffing at very similar sliding speeds. As with other fully-formulated oils, the friction trace shows some oscillations prior to the eventual scuffing failure, most likely caused by the action of additives which serves to postpone the onset of scuffing. Figure 17 shows the $P V$ chart for these oils, together with Group III base oil which is included for comparison. It is evident that both fully-formulated aviation turbine oils perform better than the 'pure' Group III oil. Out 

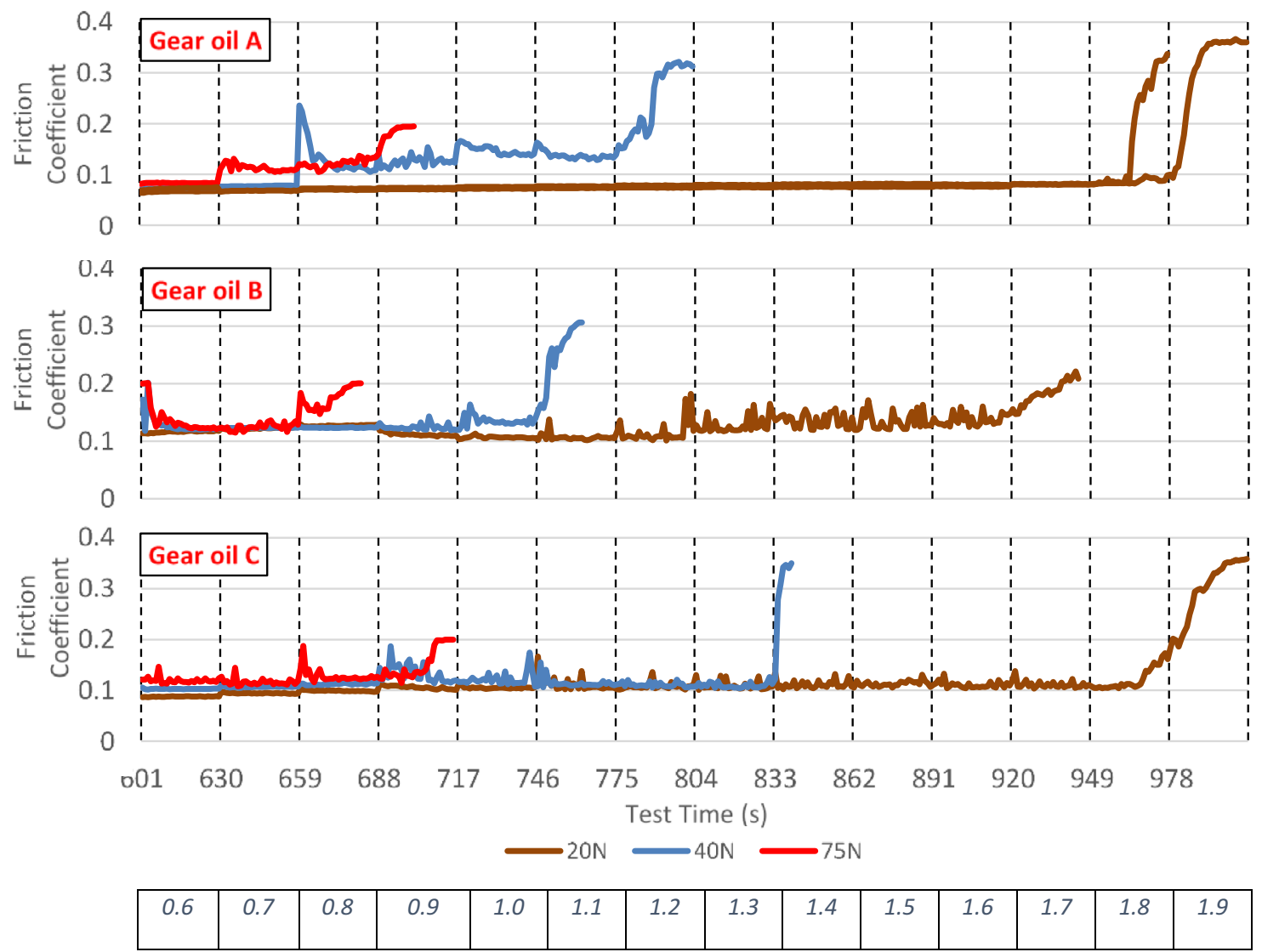

Sliding Speed $(\mathrm{m} / \mathrm{s})$

Fig. 14 Friction traces recorded during the scuffing tests with the fully-formulated oils

Fig. $15 P V$ transition chart for scuffing failure for three fullyformulated oils listed in Table 4

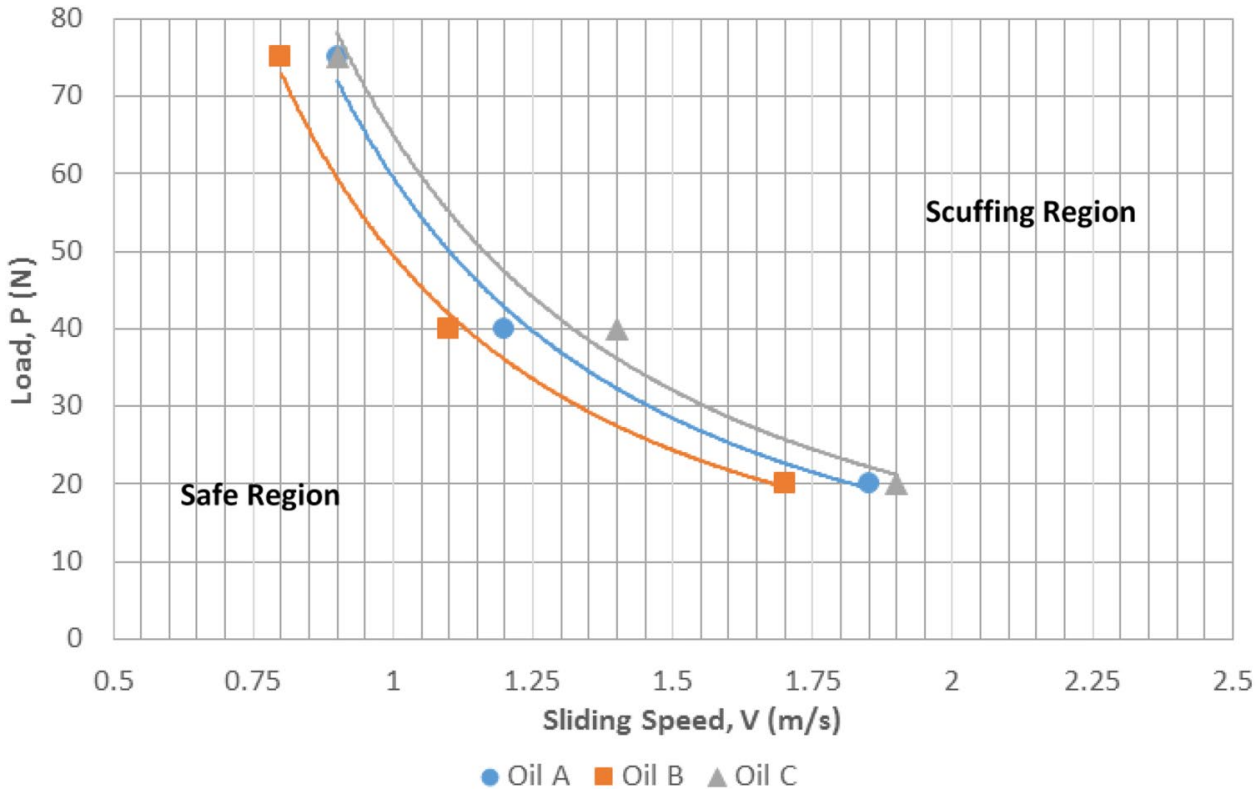




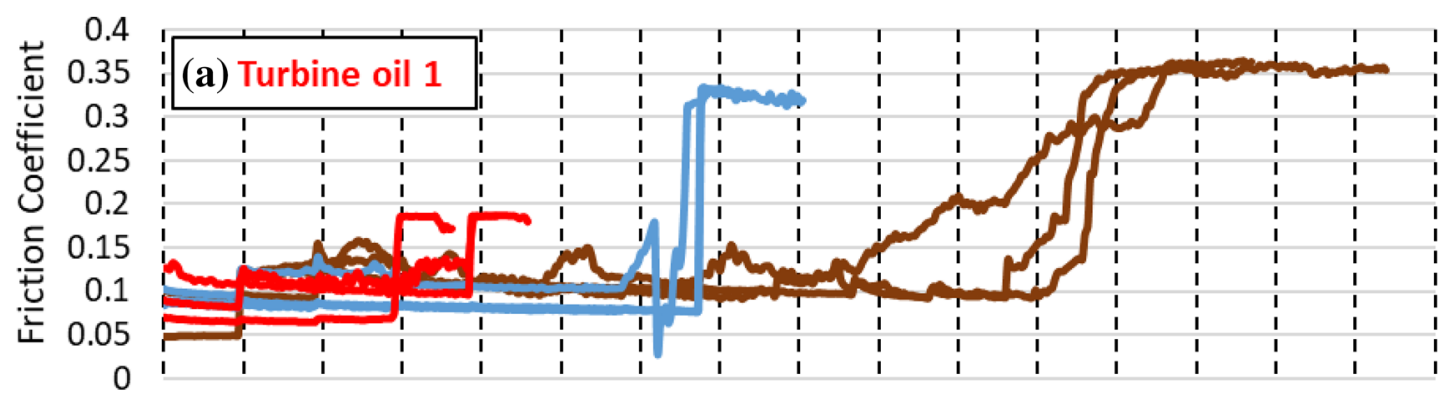

601630659688717746775804833862891920949978100710361065

Test Time (s)

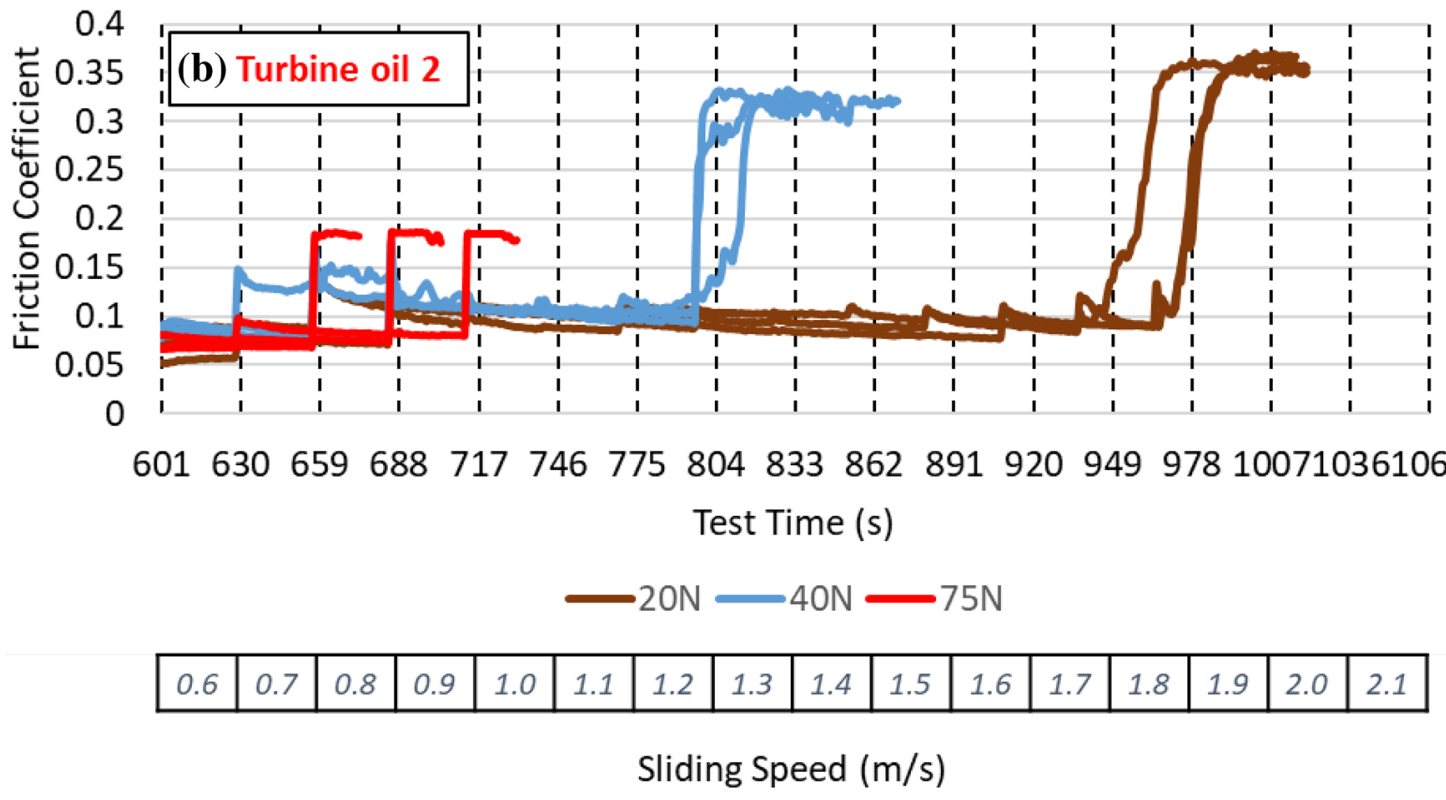

Fig. 16 Friction record from the scuffing tests with 5 cSt aviation turbine oils, a Turbine oil 1 and $\mathbf{b}$ Turbine oil 2

Fig. $17 P V$ transition chart for scuffing failure with tested aviation turbine oils, and the Group III base oil for comparison

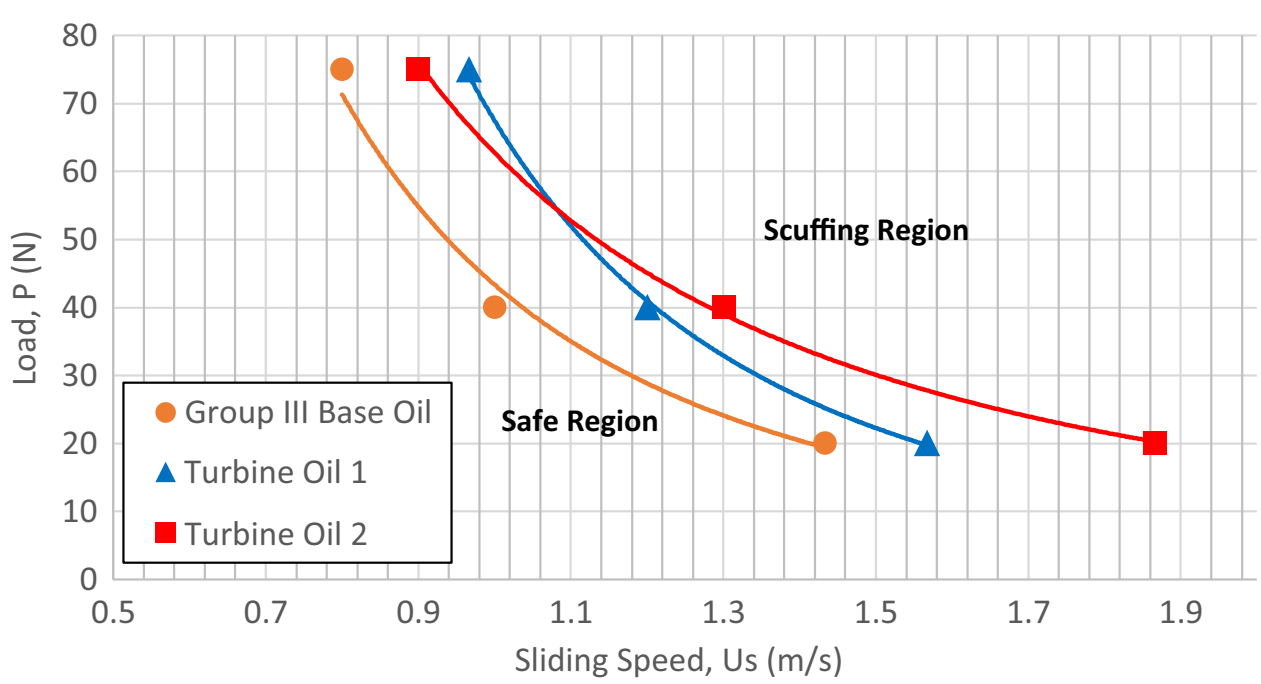


of the two turbine oils, Turbine oil 2 has slightly enhanced scuffing performance, particularly at low loads. This general trend is in line with the known Ryder gear load carrying abilities of these two oils as per MIL-PRF-23699G standard. The observed differences in performance are not very large however, which may intuitively be expected given the limited differences in formulation of the two oils.

\subsection{Scuffing Tests at Higher Pressures Using the ETM Rig}

Although the contra-rotation test method was shown to successfully and repeatedly produce scuffing, its applicability to a wider selection of oils may be limited by the maximum contact pressure achievable on the MTM (1.25 GPa with the standard 3/4 in. steel ball-on-disc configuration). To address this, the present study investigated the viability of the same method in the new ETM. This rig is similar to the MTM in all respects except that the mechanical components have been redesigned so that a much higher load can be applied to the ball-disc contact. The maximum pressure achievable in the ETM with the standard steel 3/4 in. ball and disc is 3.5 GPa. At such high pressures, and with the retained ability to operate in contra-rotation, this rig should be able to scuff most gear oils. As may be expected given this much higher maximum load, ETM's control of the loads within the low range is not as good as on the MTM. To investigate the reliability of the present scuffing method in the ETM, further tests were conducted using the same Group III base oil. The same ball and disc speeds were used for the runningin, test and rest stages as in the MTM tests. The test loads were chosen so that an overlap between the MTM and ETM
Table 7 Scuffing failure speeds obtained on the MTM and ETM over a range of loads

\begin{tabular}{llll}
\hline Load (N) & Pressure (GPa) & $\begin{array}{l}\text { MTM } \\
\text { Average failure } \\
\text { speed }(\mathrm{m} / \mathrm{s})\end{array}$ & $\begin{array}{l}\text { ETM } \\
\text { Failure speed }(\mathrm{m} / \mathrm{s})\end{array}$ \\
\hline 10 & 0.63 & No scuffing & Not applicable \\
20 & 0.85 & 1.5 & 2.7 \\
40 & 1.03 & 1 & 1.2 \\
75 & 1.25 & 0.8 & 0.8 \\
150 & 1.57 & Not applicable & 0.6 \\
300 & 1.98 & Not applicable & 0.4 \\
600 & 2.5 & Not applicable & 0.34 \\
\hline
\end{tabular}

results is obtained, providing for a direct comparison of the applicability of the method on both rigs.

Table 7 lists the scuffing speeds obtained on the ETM and MTM over a range of overlapping loads. Both sets of results are plotted on the pressure versus speed chart of Fig. 18. The test results from the two rigs overlap in the region $20 \mathrm{~N}$ to $75 \mathrm{~N}$, while above $75 \mathrm{~N}$ only ETM results are possible. At $75 \mathrm{~N}$ load, scuffing was obtained at the exact same speed of $0.8 \mathrm{~m} / \mathrm{s}$ in both set-ups. This suggests that the present scuffing method works just as well in both rigs. At $40 \mathrm{~N}$, a small discrepancy in results arises, with the scuffing speeds in the MTM and ETM being 1 and $1.2 \mathrm{~m} / \mathrm{s}$. At an even lower load of $20 \mathrm{~N}$, this discrepancy grows so that the scuffing speeds are now 1.5 and $2.7 \mathrm{~m} / \mathrm{s}$ respectively. The difference at these lower loads is almost certainly due to the inability of the ETM to accurately control the load within this low load range. Indeed, given the stiffer loading beam employed on the ETM, the rig is not intended to be used at all at such low load range.
Fig. 18 Contact pressure versus speed chart for Group III base oil showing overlapping results obtained on the MTM and ETM

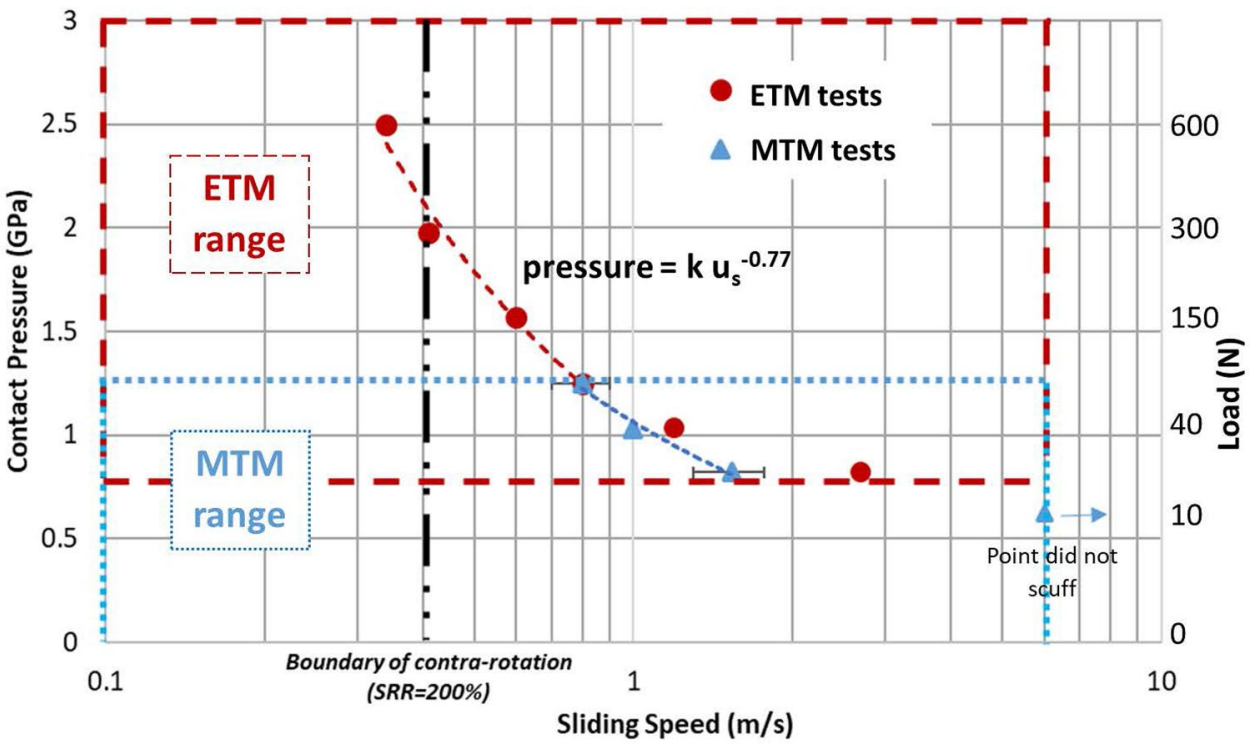


The results at loads above $75 \mathrm{~N}$ originate only from the ETM. The curve in this region follows the same shape as observed at lower loads in line with the $P V^{n}=$ constant relationship. The value of the exponent $n$ (in load $\times$ speed $^{n}=k$ ) obtained from the whole load range here is 2.31 , and the one obtained for the same Group III oil using MTM only was very similar at 2.23. These observations provide evidence that the described scuffing test can be used on the ETM in the same manner as demonstrated on the MTM so that a very wide range of $P V$ values can be covered. An additional observation is that the scuffing failure at the load of $600 \mathrm{~N}$ (2.5 GPa) occurred at a low enough sliding speed, $0.34 \mathrm{~m} / \mathrm{s}$, that only unidirectional rolling-sliding was required at the test entrainment speed of $0.2 \mathrm{~m} / \mathrm{s}$. The fact that this point follows the same $P V$ curve as all other points obtained under contra-rotation, indicates that the imposition of contra-rotation conditions does not affect the mechanism of scuffing, further confirming the validity of the method. Finally, to push the $P V$ chart into the other extreme of low load, an additional test was performed on the MTM at a load of $10 \mathrm{~N}(0.63 \mathrm{GPa})$. Scuffing did not occur even at the highest sliding speed of $6 \mathrm{~m} / \mathrm{s}$ used here.

\section{Discussion}

This paper has described development of a contra-rotation test method for studying scuffing resistance of oils under controlled conditions and its application to study the onset of scuffing with a selection of model and fully-formulated oils. In this section, the reliability of the present scuffing method is first discussed, followed by an assessment of the applicability of the existing scuffing criteria to results generated here.

\subsection{Test Repeatability}

One of the primary aims of this work was to improve the contra-rotation scuffing test so that the variability in its results is reduced. Scuffing is a sudden and catastrophic failure mode and as such its onset is sensitive to small variations in contact parameters. Therefore, some variation in scuffing results is inevitable. However, for a test to be useful this variation needs to be minimised as much as possible so that the results can be relied on without having to perform an excessive number of repeats. To explore the variability in the results of the present method, scuffing test was performed 15 times with a single oil (Group III base oil) at the same conditions. The results of these tests are presented in graphical and tabular form in Fig. 19.

It can be seen in Fig. 19 that the sliding speeds at scuffing lie in the range $1.4 \mathrm{~m} / \mathrm{s}$ and $2.2 \mathrm{~m} / \mathrm{s}$ with an average value of $1.69 \mathrm{~m} / \mathrm{s}$, indicated by the dashed line in the graph. The standard deviation of the values is $0.30 .100 \%$ of data lie within two standard deviations of the mean, and $80 \%$ of data lie within a single standard deviation of the mean. Given the nature of scuffing, this variability in results appears reasonable. These statistics manifest an improvement in test reliability over that observed by Ingram et al. [4], who found that their test results were close to normally distributed with

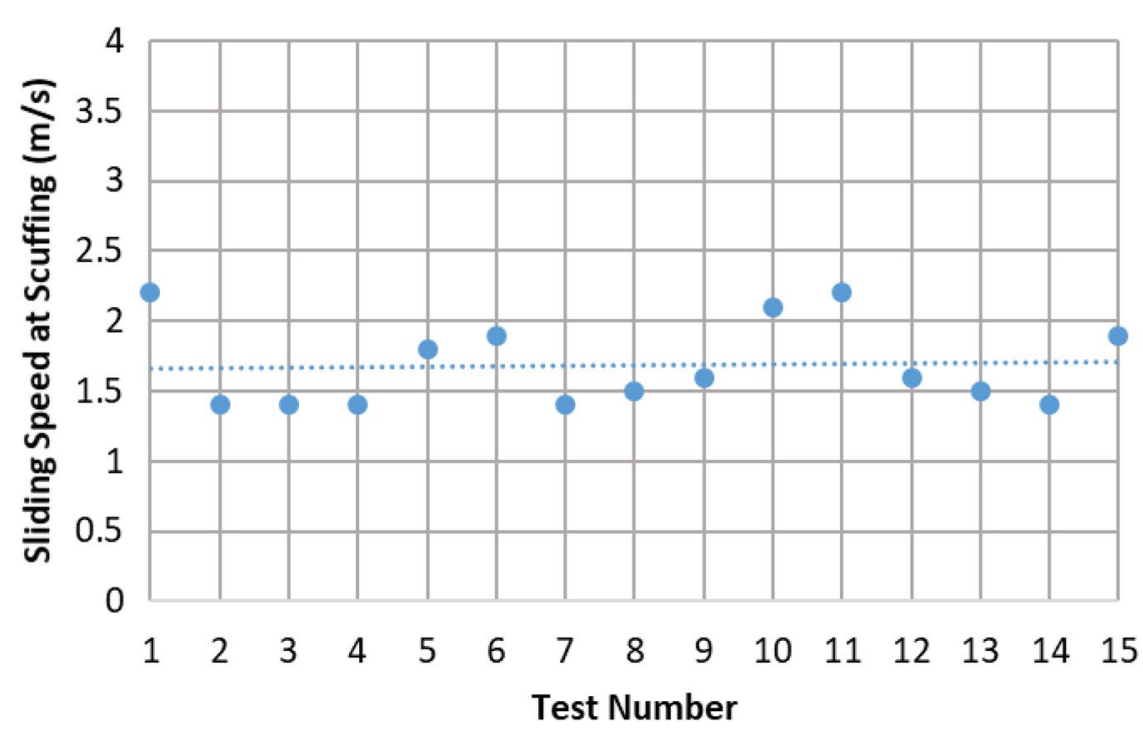

\begin{tabular}{|c|c|}
\hline $\begin{array}{c}\text { Test } \\
\text { Number }\end{array}$ & $\begin{array}{c}\text { Scuffing } \\
\text { Speed }(\mathrm{m} / \mathrm{s})\end{array}$ \\
\hline 1 & 2.2 \\
\hline 2 & 1.4 \\
\hline 3 & 1.4 \\
\hline 4 & 1.4 \\
\hline 5 & 1.8 \\
\hline 6 & 1.9 \\
\hline 7 & 1.4 \\
\hline 8 & 1.5 \\
\hline 9 & 1.6 \\
\hline 10 & 2.1 \\
\hline 11 & 2.2 \\
\hline 12 & 1.6 \\
\hline 13 & 1.5 \\
\hline 14 & 1.4 \\
\hline 15 & 1.9 \\
\hline
\end{tabular}

Fig. 19 Results of 15 repeat scuffing tests with Group III oil at the same conditions (load $20 \mathrm{~N}$, temperature $120{ }^{\circ} \mathrm{C}$, entrainment speed $200 \mathrm{~mm} / \mathrm{s}$ ) 
the standard deviation being 0.72 , based on 15 tests with the same Group III oil used here.

\subsection{Applicability of Scuffing Criteria to Present Results}

The results section showed that the transition diagrams in the form of load, $P$, versus sliding speed, $u_{\mathrm{s}}$, charts could define safe and unsafe operating regions for scuffing failure for a given oil-material combination. Such charts, often referred to as $P V$ charts, have obvious practical use in component design and lubricant selection. However, they do not provide a single-valued criterion for assessing the risk of scuffing and their production involves a considerable amount of experimental testing to cover a suitably wide range of pressures and sliding speeds. Alternative scuffing criteria in terms of a single value of a particular parameter have been proposed in literature and they are attractive for their simplicity. This section investigates the ability of two such scuffing criteria which are most widely used, Blok's maximum contact temperature [9] and the frictional power intensity (FPI) criterion of Dyson [10, 11], to predict the onset of scuffing in the present tests.

\subsubsection{Maximum Contact Temperature Criterion}

Blok's scuffing criterion says that for a given material-oil pair scuffing will occur when the maximum contact temperature reaches some critical value. As a result of frictional heating in a sliding contact, the temperature of the contacting surfaces will rise significantly above the bulk temperature of the bodies during the passage of the contact. The effect is transient and short-lived since heat is quickly dissipated into the bulk of the body so that the surface temperature returns to that of the bulk shortly after contact has passed. This transient contact temperature rise is commonly referred to as 'flash temperature' rise. The flash temperature rise is not uniform but varies across the contact area, with the maximum being located somewhere between the centre of the contact and the trailing edge with the exact location determined by the imposed contact conditions and thermal properties of the bodies. These parameters also determine the proportion of the total frictional heat generated that flows into each of the bodies, commonly referred to as the heat partition coefficient $[46,47]$. The situation is further complicated in a lubricated contact where the temperature of the oil film itself is higher than that of the surfaces. The determination of the complete temperature distribution is only possible using numerical approaches [48, 49]. However, there exist various approximate analytical expressions that can be used to obtain good estimates of the maximum and mean contact temperatures, with those due to Blok [46] and
Jaeger [47] the most widely used. These are limited in terms of contact shape and/or the range of Peclet numbers to which they apply and rely on an approximate value of heat partition coefficient. One such approximate approach is used here to estimate the maximum contact temperature rise so that the applicability of Blok's scuffing criteria to present scuffing results can be evaluated.

In the absence of an appreciable fluid film, the maximum contact temperature is equal to the sum of the body bulk temperature, $T_{\mathrm{b}}$, and the maximum transient surface flash temperature rise, $\Delta T_{\text {flash }}$ :

$T_{\max }=T_{\mathrm{b}}+\Delta T_{\text {flash }}$

A simple expression due to Kennedy [50] is used here to calculate the maximum flash temperature rise. This expression is directly applicable to a circular contact with a parabolic heat flux distribution, as is the case here, and to any Peclet number. It reads:

$\Delta T_{\text {flash }}=\frac{2.32 \alpha_{\mathrm{p}} \bar{q}^{\prime \prime} a}{k \sqrt{\pi(1.234+P e)}}$,

where $k$ is the thermal conductivity of the surface material (steel in the present case) and $a$ is the radius of the contact calculated from the Hertz contact theory for a point contact,

$a=\left(\frac{3 P R}{4 E^{*}}\right)^{1 / 3}$,

where $P$ is the applied load, $R$ is the radius of the ball and $E^{*}$ is the reduced elastic modulus.

$q^{\prime \prime}$ is the mean rate of frictional heat generation $\left(\mathrm{W} / \mathrm{m}^{2}\right)$,

$\bar{q}^{\prime \prime}=\mu \bar{p} u_{\mathrm{s}}$,

where $\mu$ is the friction coefficient, $\bar{p}$ is the mean contact pressure and $u_{\mathrm{s}}$ is the sliding speed.

$\alpha_{\mathrm{p}}$ is the proportion of the generated heat going into the body being considered; $\left(1-\alpha_{\mathrm{p}}\right)$ goes into the other body. In reality, the heat partition fraction, $\alpha_{\mathrm{p}}$ varies across the contact so that a numerical approach is required for its accurate determination $[48,49]$, but a common approximate approach, which assumes a constant value across the contact, is to estimate it by equating the flash temperatures of the two bodies (see Eq. 6) and solving the resulting expression for $\alpha_{\mathrm{p}}$ [46, 47, 50].

$P e$ denotes the Peclet number,

$P e=\frac{u_{\mathrm{s}} a \rho c_{\mathrm{p}}}{2 k}$,

where $\rho$ is the density and $c_{\mathrm{p}}$ is the specific heat capacity of the surface material.

Following this procedure, values of maximum contact temperature at the onset of scuffing were calculated for all 
Fig. 20 Plot of predicted maximum contact temperature at scuffing against mean contact pressure for tests with the four model oils

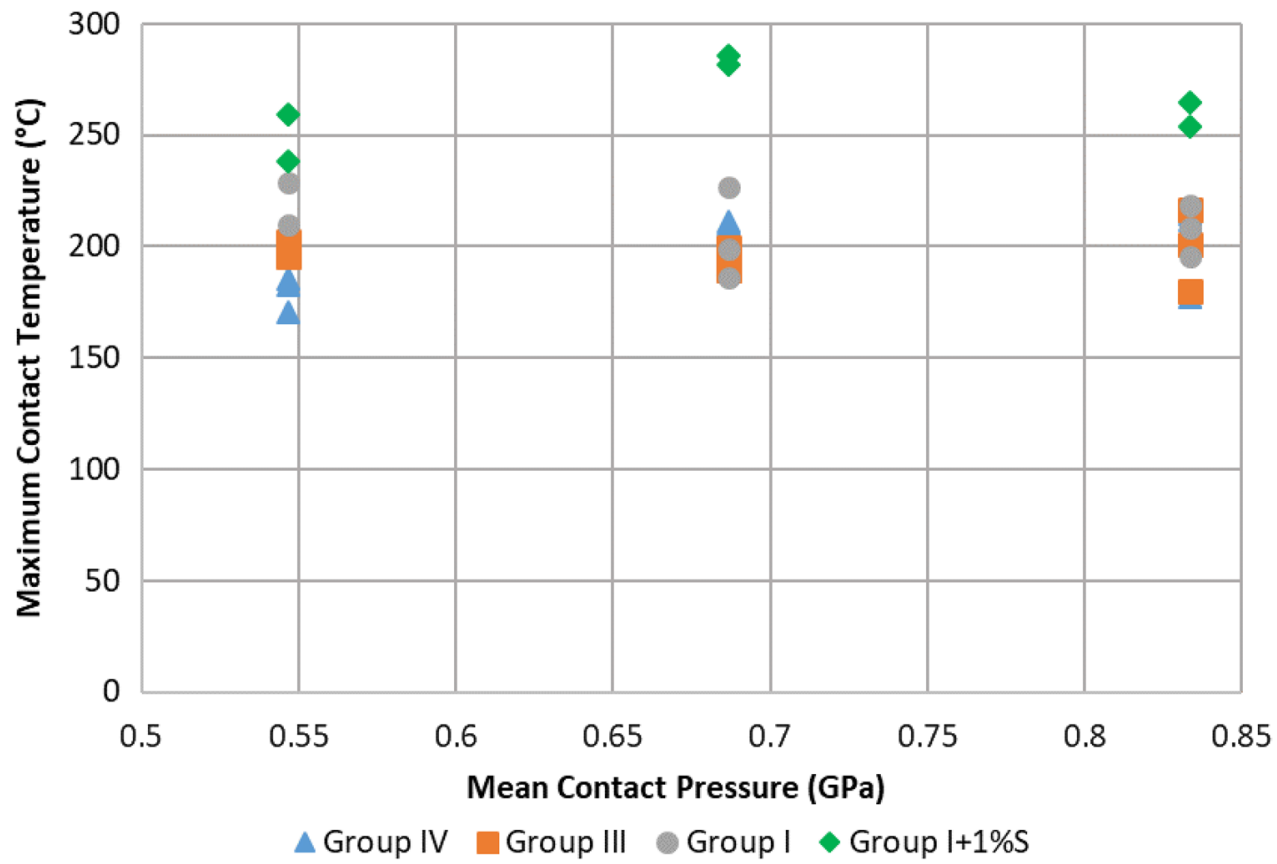

tests with model and fully-formulated industrial oils. In each case, the value of the measured friction coefficient just prior to the onset of scuffing was used in the calculations. Figure 20 plots these maximum contact temperatures against mean contact pressure for tests with Groups I, III and IV base oils and Group I $+1 \mathrm{wt} \% \mathrm{~S}$ oil. Figure 21 shows the same plot for the tests with the three fully-formulated industrial oils. It is evident in both figures that for each oil, the predicted maximum contact temperature at scuffing remains relatively constant across all pressures. In addition, it can also be seen that the maximum contact temperature at scuffing for all EP additive containing oils is higher, with the mean value of about $260{ }^{\circ} \mathrm{C}$ for Group $\mathrm{I}+1 \% \mathrm{~S}$ and $210^{\circ} \mathrm{C}$ for the three industrial oils, than that for the three base oils, which all have the mean of about $200{ }^{\circ} \mathrm{C}$. Therefore, these results provide support for Blok's critical maximum contact
Fig. 21 Plot of predicted maximum contact temperature at scuffing against mean contact pressure for tests with three fully-formulated industrial oils

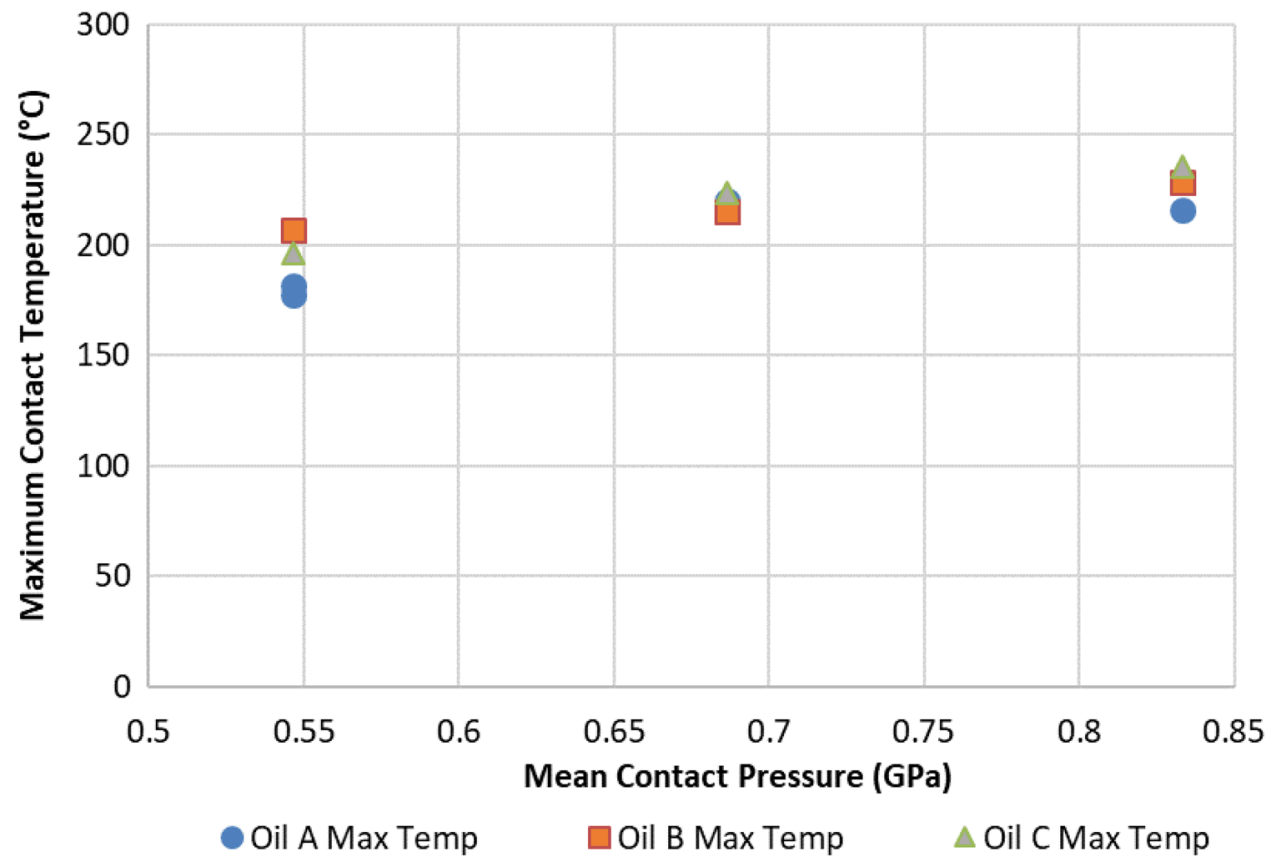


temperature scuffing criterion, which appears to be able to not only predict the point of scuffing for a given oil, but also to successfully differentiate between two oils with different scuffing resistance. The in-contact temperature influences the boundary film strength but does not affect the EHL film thickness. Thus, the most probable reason for the observed constancy of temperature at scuffing is the fact that the present tests are designed to test the effect of lubricant chemical composition on scuffing, while excluding the effect of oil viscosity on the EHL film.

\subsubsection{Frictional Power Intensity (FPI) Criterion}

The contact mean FPI, $\stackrel{-\prime}{q}^{\prime \prime}\left(\mathrm{W} / \mathrm{m}^{2}\right)$, at scuffing is given by:

$\mathrm{FPI}=\bar{q}^{\prime \prime}=\mu \cdot \bar{p} \cdot u_{\mathrm{s}}$,

where $\mu$ is the friction coefficient just prior to the onset of scuffing (i.e. before the spike in friction), $p$ is the mean contact pressure, and $u_{\mathrm{s}}$ is the sliding speed at the point of scuffing. The value of FPI was evaluated for all tests with the model and fully-formulated oils tested here. Figure 22 shows FPI at scuffing plotted against mean contact pressure for tests with Group I, III and IV base oils and Group I+ $1 \%$ S oil. Figure 23 shows the same plot for the three fully-formulated oils. It can be seen that FPI is not constant at the onset of scuffing for any given oil. In fact, there appears to be a general trend for reducing FPI with increasing pressure. Therefore, FPI appears not to be as reliable an indicator of the onset of scuffing in the present tests as the maximum contact temperature which was shown above to have a relatively more constant value at the onset of scuffing for a given oil. Dyson [18] also suggested that FPI at scuffing may decrease with increasing severity of contact conditions and, although Dyson considered different contact parameters, the general trend of decreasing FPI with increasing pressure seen here is in line with this suggestion. Nevertheless, FPI at scuffing appears able to distinguish between oils with different scuffing performance, with its value for the Group $\mathrm{I}+1 \% \mathrm{~S}$ oil being consistently higher $\left(\sim 230 \mathrm{MW} / \mathrm{m}^{2}\right.$ at low pressures, dropping to $\sim 130 \mathrm{MW} / \mathrm{m}^{2}$ at the highest pressure) than that for the pure base oils $\left(\sim 120 \mathrm{MW} / \mathrm{m}^{2}\right.$ at low pressures, dropping to $\sim 70 \mathrm{MW} / \mathrm{m}^{2}$ at the highest pressure).

The three different ways of identifying the conditions leading to the onset of scuffing discussed here, namely the $P u_{\mathrm{s}}{ }^{n}=k$ relationship shown on the load versus sliding speed charts, the maximum in-contact temperature and the total frictional heat are related since all three describe thermal effects in the contact. However, there is no simple relationship between these parameters owing to the complexities of contact thermal responses, not least those due to the manner in which the total generated frictional heat is partitioned between the contacting bodies. This is described through heat partition fraction which depends on the speed of the bodies relative to the contact, their relative thermal properties and contact size. Together these parameters define the Peclet number (Eq. 9). For this reason, the maximum contact temperature at scuffing does not necessarily exhibit the same trend as the total frictional heat produced in the contact, as is evident when comparing Figs. 20 and 21 with Figs. 22 and 23. Ultimately, which of the contact thermal parameters best
Fig. 22 Plot of mean frictional power intensity at scuffing against mean contact pressure for tests with the four model oils

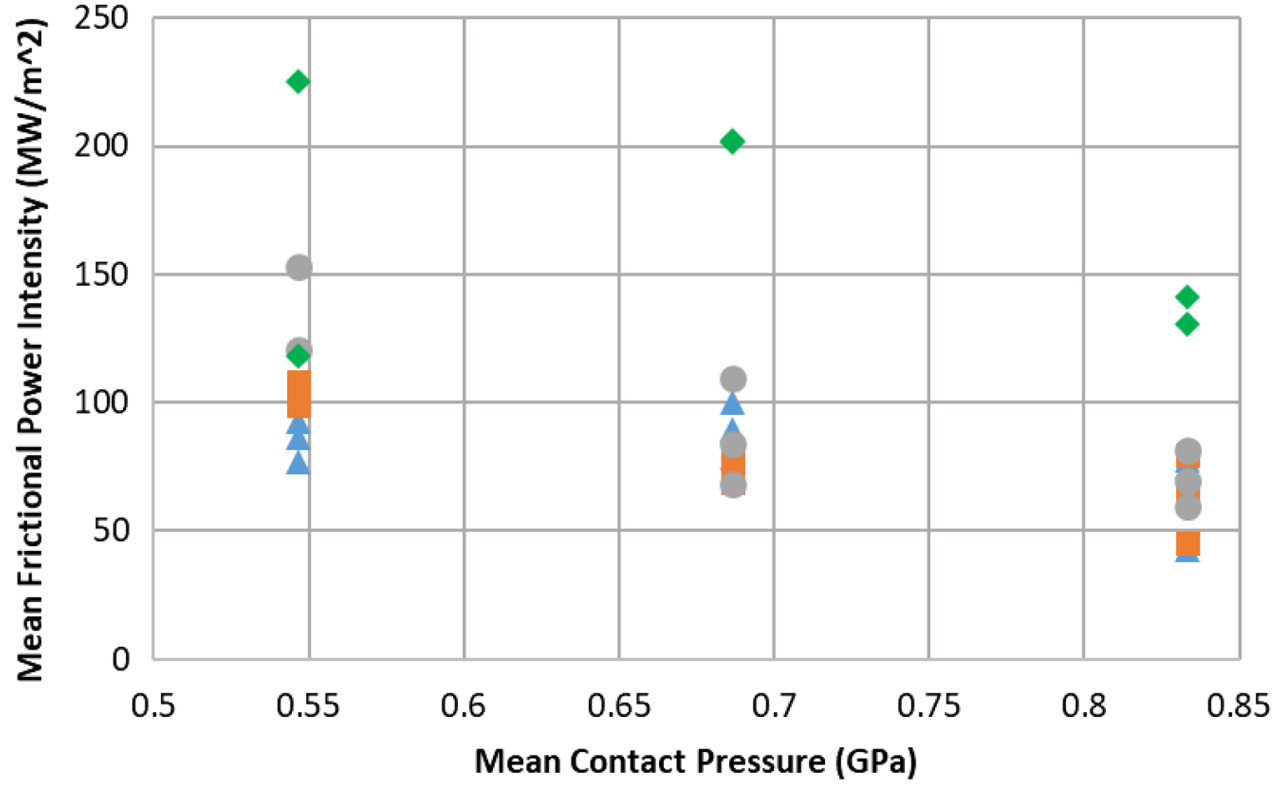

$\triangle$ Group IV Group III Group I • Group I+1\%S 
Fig. 23 Plot of mean frictional power intensity at scuffing against mean contact pressure for tests with the three fullyformulated industrial oils

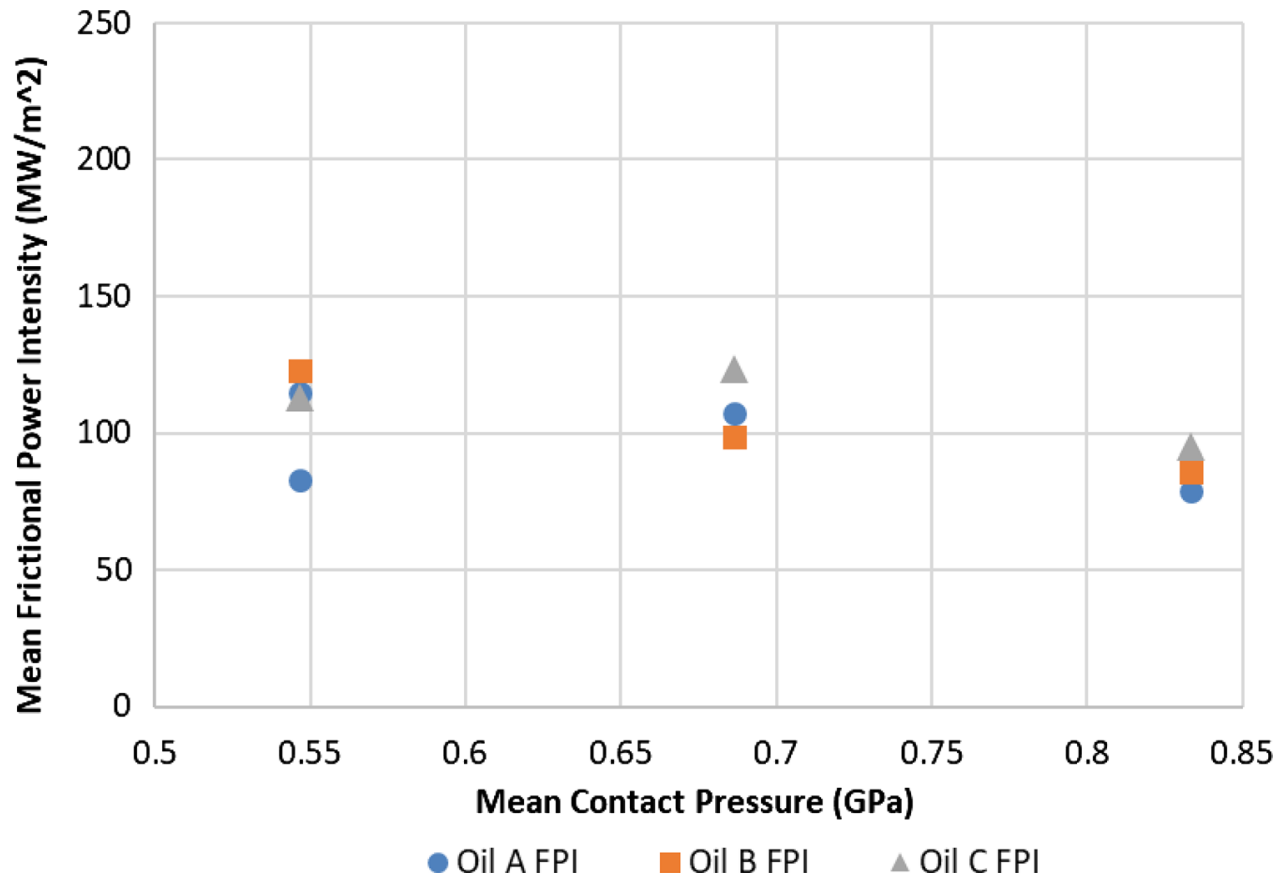

describes the conditions at the onset of scuffing will depend on the precise mechanism of scuffing for a given material-oil combination. For example, the critical maximum in-contact temperature criterion would suggest that it is the breakdown of the boundary film, rather than the hydrodynamic film that determines the onset of scuffing, since the latter is related to the contact inlet temperature.

\section{Conclusions}

This paper describes the development of a scuffing test method based on contra-rotation, and its application to study scuffing resistance of a selection of model and fullyformulated oils. The method employs two surfaces moving in opposite direction under rolling-sliding conditions, with a fixed load and step-wise increasing sliding speed. The method was first implemented on the PCS MTM and successfully extended here to a higher load range using the PCS ETM. The test has the following advantages:

- It decouples the entrainment and sliding speeds, which allows for the effect of the oil chemical composition on its scuffing performance to be established independently of its viscosity.

- It allows for high sliding speeds to be reached while maintaining a low entrainment speed so that high performance oils can be tested successfully.

- Step-wise increase in sliding speed, rather than load, eliminates the adverse effects of fresh asperities being brought into contact at start of each test step.
- Effects of wear are minimised due to use of rolling-sliding conditions.

- Inclusion of a 'rest' stage after each test stage minimises the effects of frictional heating.

- Use of SLIM allows the boundary film to be monitored during the test, so that the mechanism of scuffing can be better defined.

The test method was shown to be able to reliably produce scuffing with a selection of base and model oils, as well as fully-formulated industrial oils. The results show that:

- The improvements to the original contra-rotation method that were implemented here have reduced the variability in obtained results. Three repeat tests are considered sufficient to establish the conditions at scuffing with high confidence.

- A central 'dimple' may form in contra-rotation when sliding speeds are high, but it is not present under conditions employed in the present test.

- The onset of scuffing is identified by a sharp and unrecoverable increase in friction coefficient.

- Oils that contain sulphur based additives have enhanced scuffing performance relative to pure base oils.

- When the effect of viscosity is excluded, fully-formulated oils from the same series, and hence with the same additive package, have the same scuffing performance.

- The load versus sliding speed plots ( $P V$ charts) for all oils show that at scuffing the relationship $P V^{n}=$ constant holds. The exact value of the exponent $n$ is determined 
by the oil and in the present tests ranges between 1.7 and 3.2 .

- The maximum contact temperature scuffing criterion predicts the onset of scuffing in the present tests more reliably than the FPI criterion.

Open Access This article is distributed under the terms of the Creative Commons Attribution 4.0 International License (http://creativeco mmons.org/licenses/by/4.0/), which permits unrestricted use, distribution, and reproduction in any medium, provided you give appropriate credit to the original author(s) and the source, provide a link to the Creative Commons license, and indicate if changes were made.

\section{References}

1. Institution of Mechanical Engineers: Memorandum on definitions, symbols and units. In: Conference on Lubrication and Wear, Proceedings of Institute of Mechanical Engineers, London, vol. 4 (1957)

2. Musgrave, F.F.: The development and lubrication of the automotive hypoid gear. J. Inst. Pet. 32, 32-44 (1946)

3. Schipper, D.J., De Gee, A.W.J.: Lubrication modes and the IRG transition diagram. Lubr. Sci. 8(1), 27-35 (1995)

4. Ingram, M., Hamer, C., Spikes, H.: A new scuffing test using contra-rotation. Wear 328-329, 229-240 (2015)

5. De Gee, A.W.J., Begelinger, A., Salomon, G.: Failure mechanisms in sliding lubricated concentrated contacts. In: Proceedings of 11th Leeds-Lyon Symposium on Tribology, Mixed Lubrication and Lubricated Wear, Leeds, 1984, pp. 105-124

6. Fowell, M., Ioannides, S., Kadiric, A.: An experimental investigation into the onset of smearing damage in nonconformal contacts with application to roller bearings. Tribol. Trans. 57(3), 472-488 (2014)

7. Evans, R.D., Barr, T.A., Houpert, L., Boyd, S.V.: Prevention of smearing damage in cylindrical roller bearings. Tribol. Trans. 56(5), 703-716 (2013)

8. Moosavian, A., Najafi, G., Ghobadian, B., Mirsalim, M., Jafari, S.M., Sharghi, P.: Piston scuffing fault and its identification in an IC engine by vibration analysis. Appl. Acoust. 102, 40-48 (2016)

9. Blok, H.: Surface temperature measurements on gear teeth under extreme pressure lubricating condition. Proc. Inst. Mech. Eng. 2, 14-20 (1937)

10. Bell, J.C., Dyson, A.: Effect of some operating factors on the scuffing of hardened steel discs. In: Institute of Mechanical Engineers Elastohydrodynamic Lubrication 1972 Symposium, Leeds, 1973, pp. 61-67 (1972)

11. Dyson, A.: The Failure of elastohydrodynamic lubrication of circumferentially ground discs. Proc. Inst. Mech. Eng. 190(1), 699-711 (1976)

12. Hirst, W., Hollander, A.E.: Surface finish and damage in sliding. Proc. R. Soc. Lond. A 337(1610), 379-394 (1974)

13. Enthoven, J., Spikes, H.A.: Infrared and visual study of the mechanisms of scuffing. Tribol. Trans. 39(2), 441-447 (1996)

14. Spikes, H.A., Cameron, A.: Scuffing as a desorption processan explanation of the Borsoff effect. ASLE Trans. 17(2), 92-96 (1974)

15. Hershberger, J., Ajayi, O.O., Zhang, J., Yoon, H., Fenske, G.R.: Evidence of scuffing initiation by adiabatic shear instability. Wear 258(10), 1471-1478 (2005)
16. Ajayi, O.O., Lorenzo-Martin, C., Erck, R.A., Fenske, G.R.: Analytical predictive modeling of scuffing initiation in metallic materials in sliding contact. Wear 301, 57-61 (2013)

17. Ajayi, O.O., Lorenzo-Martin, C., Erck, R.A., Fenske, G.R.: Scuffing mechanism of near-surface material during lubricated severe sliding contact. Wear 271, 1750-1753 (2011)

18. Dyson, A.: Scuffing - a review (Part I). Tribol. Int. 8(2), 77-87 (1975)

19. Ludema, K.C.: A review of scuffing and running-in of lubricated surfaces, with asperities and oxides in perspective. Wear 100(1), 315-331 (1984)

20. Bowman, W.F., Stachowiak, G.W.: A review of scuffing models. Tribol. Lett. 2(2), 113-131 (1996)

21. ASTM D2596: Standard Test Method for Measurement of Extreme-Pressure Properties of Lubricating Grease (Four-Ball Method)

22. ASTM D2782: Standard Test Method for Measurement of Extreme-Pressure Properties of Lubricating Grease (Timken Method)

23. American Society for Testing and: Materials: ASTM D1947 Test Method for, Load-Carrying Capacity of Petroleum Oil and Synthetic Fluid Gear Lubricants (1993)

24. Energy Institute (formerly Institute of Petroleum, IP): IP 166 77(R1992) Determination of Load-Carrying Capacity of Lubricants-IAE Gear Machine Method

25. ISO: ISO 14635 Part 1: Gears-FZG Test Procedures-Part 1: FZG Test Method A/8,3/90 for Scuffing 1736 Load-Carrying Capacity of Oils, 2000 (2000)

26. Meng, X., Wang, J., Zhang, B., Zou, Q.: Effect of oil starvation on the surface dimple in elastohydrodynamic lubrication contact under opposite sliding conditions. Proc. Inst. Mech. Eng., Part J: Journal of Engineering Tribology 231(8), 1016-1029 (2017)

27. Guo, F., Wong, P.L., Yang, P., Yagi, K.: Film formation in EHL point contacts under zero entraining velocity conditions. Tribol. Trans. 45(4), 521-530 (2002)

28. Guo, F., Yang, P., Qu, S.: On the theory of thermal elastohydrodynamic lubrication at high slide-roll ratios-circular glasssteel contact solution at opposite sliding. J. Tribol. 123(4), 816 (2001)

29. Blok, H.: Gear wear as related to viscosity of gear oils. In: Proceedings of Summer Conference-MIT, Mechanical Wear, vol. 61(25), pp. 199-227 (1948)

30. Nakahara, T., Yagi, K.: Influence of temperature distributions in EHL film on its thickness under high slip ratio conditions. Tribol. Int. 40(4), 632-637 (2007)

31. PCS Instruments: MTM 2 Mini-traction Machine (2013). http:// pcs-instruments.com/wp-content/uploads/2014/03/MTM2.pdf

32. Mezghani, S., Demirci, I., Yousfi, M., El Mansori, M., Mezghani, S., Demirci, I., Yousfi, M., Mansori, M.El: Running-in wear modeling of honed surface for combustion engine cylinder liners. Wear 302, 1360-1369 (2013)

33. Sugimura, J., Kimura, Y., Amino, K.: Analysis of the topography changes due to wear-geometry of the running-in process. J. Jpn Soc. Lubr. Eng. 33(11), 813-820 (1986)

34. Thomas, T.R.: Rough Surfaces, vol. 2. Imperial College Press, London (1999)

35. Guegan, J., Kadiric, A., Spikes, H.: A study of the lubrication of EHL point contact in the presence of longitudinal roughness. Tribol. Lett. 59(1), 22 (2015)

36. Guegan, J., Kadiric, A., Gabelli, A., Spikes, H.: The relationship between friction and film thickness in EHD point contacts in the presence of longitudinal roughness. Tribol. Lett. 64(3), 33 (2016)

37. Morales-Espejel, G. E., Rycerz, P., Kadiric, A.: Prediction of micropitting damage in gear teeth contacts considering the 
concurrent effects of surface fatigue and mild wear. Wear 398, 99-115 (2018)

38. Lee-Prudhoe, I., Sayles, R.S., Kaderic, A.: Investigations into asperity persistence in heavily loaded contacts. J. Tribol. 121(3), 441-448 (1999)

39. Kadiric, A., Jalisi, I., Sayles, R.: Influence of entrapped fluid in rough surface contacts. In: Proceedings of JAST International Tribology Conference ITC, Nagasaki 2000, pp. 283-288 (2001)

40. Kaneta, M., Nishikawa, H., Kameishi, K., Sakai, T., Ohno, N.: Effects of elastic moduli of contact surfaces in elastohydrodynamic lubrication. J. Tribol. 114(75), 75-80 (1992)

41. Yang, P., Qu, S., Kaneta, M., Nishikawa, H.: Formation of steady dimples in point TEHL contacts. J. Tribol. 123(1), 42-49 (2001)

42. Nishikawa, H., Kanada, T., Matsuda, K.: Abnormal phenomena appearing in EHL contacts. J. Tribol. 118, 886-892 (1996)

43. Yagi, K., Kyogoku, K., Nakahara, T.: Relationship between temperature distribution in EHL film and dimple formation. J. Tribol. 127(3), 658 (2005)

44. Bruyere, V., Fillot, N., Morales-Espejel, G.E., Vergne, P.: Computational fluid dynamics and full elasticity model for sliding line thermal elastohydro dynamic contacts. Tribol. Int. 46(1), 3-13 (2012)

45. Cann, P.M., Spikes, H.A., Hutchinson, J.: The development of a spacer layer imaging method (SLIM) for mapping elastohydrodynamic contacts. Tribol. Trans. 39(4), 915-921 (1996)

46. Blok, H.: Theoretical study of temperature rise of surfaces of actual contact under oiliness lubricating conditions. In: Proceedings of General Discussion on Lubrication, Part 2, p. 222. Institution of Mechanical Engineers, London (1937)

47. Jaeger, J.: Moving sources of heat and the temperature of sliding contacts. J. Proc. R. Soc. N. S. W. 76, 203-224 (1942)

48. Kadiric, A., Sayles, R.S., Ioannides, E.: Thermo-mechanical model for moving layered rough surface contacts. J. Tribol. 130(1), 011016 (2008)

49. Hajishafiee, A., Kadiric, A., Ioannides, S., Dini, D.: A coupled finite-volume CFD solver for two-dimensional elasto-hydrodynamic lubrication problems with particular application to rolling element bearings. Tribol. Int. 109, 258-273 (2017)

50. Kennedy, F.E.: Determination of contact temperatures resulting from frictional heating. In: Proceedings of JAST International Tribology Conference ITC Nagasaki 2000, pp. 313-318 (2001)

Publisher's Note Springer Nature remains neutral with regard to jurisdictional claims in published maps and institutional affiliations. 